فعالية برنامج تدرببي قائم على الفن التشكيلي لخفض سلوك التنمر وتحسين الكفاءة الاجتماعية لاى طلاب المرحلة الثانوية لية لئية

بحث مشتق من رسالة مقدمة للحصول على درجة الماجستير في التربية

تخصص صحة نفسية

مقدمة من

صفاء إبراهيم عبد الله بحيري

\title{
تحت إثراف
}

أ.د / جمعة حسين عبد الجواد

قسم التربية الفنية

كلية التربية النوعية جامعة المنوفية

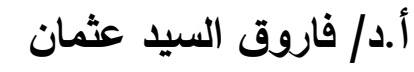

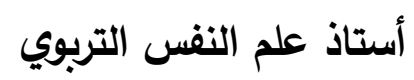

كلية التربية جامعة مدينة السادات 
بعد الاستغراق في الجوانب السلبية المضطربة للسلوك الإنساني وبالأخص في مرحلة المراهقة التي تُعد فترة توتر وأزمات نفسية ومعاناه وإحباط وصراعات وقلق وكذا تتمر الذي يخفي خلفه ثورة عارمة من المشكلات والنوايا المبيته بالأذى للآخرين، ومجموعة من الانحرافات السلوكية وفقدان الانسجام الوجداني ، والغضب والعناد وما إلى ذلك من مظاهر عدم التكيف الاجتماعي، والسير بغير هدف لمدة طويلة، مما يزيد الانحرافات السلوكية. حيث إن من خصائص المرحلة الانفعالات العنيفة والمتقلبة كالحزن واليأس نتيجة لبعض الإحباطات بسبب تقاليد المجتمع التي تَحُول بينه وبين تحقيق أمانيه وهذا الإحباط كثيراً ما يؤدي إلى انخفاض الكفاءة الاجتماعية والتفكير في سلوكيات جانحة كالانتحار أو التنمر بالمحيطين به مما اقتضى إلى عمل برنامج تدريبي قائم على الفن التشكيلي للحد من السلوكيات السلبية لا سيما سلوك التنمر • حيث إن ممارسة الفن التشكيلي تُحول صور العنف والثورة إلى جمال فني باستخدام عناصر ورموز مختلفة بواسطتها يتحرر الفرد من أفكاره السلبية وتتزايد لديه الرغبة في المشاركة الاجتماعية وبالتالي تتحسن الكفاءة الاجتماعية، ولأن الفن نوع من التطهير أو التخلص من الطاقة المكبوتة داخل الفرد "وأن عالم اللاشعور يتحكم في التعبير الفني بطريقة غير مباشرة، عثر على أثر اللاشعور في ثورة فنانين كثر على مواقف ضد الضمائر المثقلة بالخطايا"(محسن عطية، ب . ب؟).

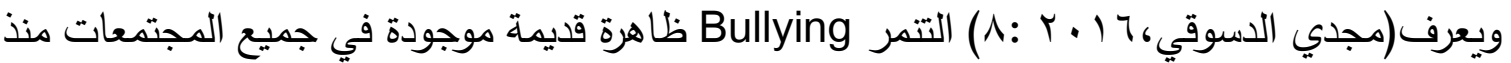
زمن بعيد لدى أفراد الجنس البشري حيث يمارسونه بأشكال مختلفة وبدرجات متفاوتة، وتظهر عندما تتوافر الظروف المناسبة، وعلى الرغم من أن السلوك التمري Bullying Behavior موجوداً في المجتمعات البشرية منذ القدم إلا أن البحث في هذا الموضوع حديثا نسبياً ويُعد السلوك التتمر عندما يشمل هجوماً نفسياً ولفظياً وبدنياً غير مستثار على الضحية Victim، ويبدأ هذا السلوك في عمر مبكر من الطفولة في حوالي السنتين تقريباً؛ حيث يبدأ الطفل في تشكيل مفهوم أولي للتتمر ينمو تدريجياً ويتمر حتى يصل إلى ونى الذروة في الصفوف الثلاثة الأولى من المرحلة الابتدائية ويتتر خلال المرحلة الإعدادية ثم يبدأ في الهبوط تدريجياً مع نهاية المرحلة الثانوية، وقلما يوجد سلوك تتمري في المرحلة الجامعية باستثناء حالات السخرية.

\section{مشكلة الاراسة}

يُعد التتمر من المشكلات النغسية التي تؤثر على حياة الفرد وكفاءته اجتماعياً كما يمثل خطورة على حياة الأفراد اجتماعيا. وفي المدارس العديد من السلوكيات العدوانية كالإساءة الجسدية واللفظية والتخربب المتعدد، وعدم الانصياع للقواعد والتعليمات والإصرار على إلحاق الأذى بالأفراد الضعفاء ويعد هذا تتمراً سلوكياً يحدث بصورة متكرة. ومن هنا نبعت مشكلة الدراسة وإحساس الباحثة بأهمية متغيرات الدراسة 
الحالية : التتمر المدرسي ، الكفاءة الاجتماعية كبرامج الفن التشكيلي لتحقيق التوافق المجتمي وخاصة في الوسط المدرسي ، ويعد التتمر المدرسي من أكثر السلوكيات انتشاراً بين الطلبة في جميع المراحل التعليمية بوجه عام وبالأخص في مرحلة المراهقة ويعتبر هذا السلوك من أشد السلوكيات خطورة وذلك لما يترتب عليها من نتائج سلبية على الطلاب وعلى باقي عناصر العملية التعليمية التي تعوق كل من الطرفين في إتمام العملية التعليمية وتحقيق الأهداف المرجوة . إضافة لأهمية هذه المرحلة العدرية التي تقابل مرحلة النمو المتأخرة والمراهقة المتوسطة والتي تتميز بخصائص عامة منها السرعة في مظاهر النمو جسديا و حركيا وعقليا وانفعاليا مما ينتج عنه مشكلات لاى الطلاب تتطلب معالجتها تربويا ونفسيا لمساعدتهم على تخطي المرحلة بسلام ومن هنا جاءت الحاجة إلى دراسة التتمر المدرسي لطلاب المرحلة الثانوية. وتحددت مشكلة الدراسة في التساؤل الرئيسي : - ما فعالية برنامج قائم على الفن التشكيلي في خفض سلوك التنمر وتحسين الكفاءة الاجتماعية لدى طلاب المرحلة الثانوية ؟ ويتفرع من هذا السؤال الرئيسي التساؤلات الفرعية التالية: ا-هل توجد فروق في سلوك التنمر المدرسي قبل وبعد تطبيق البرنامج ؟ r- هل توجد فروق في القياس البعدي والتتبعي في سلوك التتمر المدرسي؟ r-هل يوجد فروق في الكفاءة الاجتماعية قبل وبعد تطبيق البرنامج؟ ع- هل توجد فروق في القياس البعدي والتتبعي في الكفاءة الاجتماعية؟ أهداف الدراسة تهدف الدراسة الحالية إلى التعرف على فعالية برنامج قائم على الفن التشكيلي لخفض سلوك التتمر وتحسين الكفاءة الاجتماعية لدى طلاب المرحلة الثانوية.

أهمية الدراسة ونينة

ترجع أهمية الدراسة إلى أهمية الموضوع الذي نتناوله وهو التنمر المدرسي وهذا لانتشاره بين الطلاب في جميع المراحل التعليمية ومن ثم نقدم إضافة تربوية من خلال استخدام برنامج تدريبي يخفض هذه السلوكيات ويحسن الكفاءة الاجتماعية لدى الطلاب. ويمكن إيضاح أهمية الدراسة في بعديها النظري والتطبيقي على النحو التالي : الأهمية النظرية إن الكثير من الدراسات والبحوث التي أجريت في دراسة مرحلة المراهقة وأزماتها متنوعة إلا أن تناول موضوع التتمر المدرسي وتحسين الكفاءة الاجتماعية بآلية جديدة وهي البرنامج التدريبي القائم على الفن التشكيلي يعد من الطرق الحديثة لحل مشكلات هذه المرحلة والحد من الاضطرابات الانفعالية والسلوكية . 


\section{الأهمية التطبيقية}

يمكن أن توفر نتائج الدراسة الحالية البيانات والمعلومات التي تساعد في التخطيط السليم للتصدي لمشكلة التتمر المدرسي، وتحسين كفاءة الطلاب في هذه المرحلة كما نأمل أن يستفيد المرشدين والمدرسين من نتائج الدراسة في توجيه وتدريب وضبط السلوكيات من خلال البرنامج المتبع بهدف اتاحة الفرصة للتفاعل الاجتماعي والتوافق النفسي مع الأقران داخل وخارج المدرسة.

منهج الاراسة

المنهج شبه التجريبي حيث إن المتغير المستقل هو البرنامج القائم على الفن التشكيلي والمتغير التابع هو سلوك التنمر والكفاءة الاجتماعية. أدوات الدراسة

ا-برنامج تدريبي قائم على الفن التشكيلي لتحسين الكفاءة الاجتماعية وخفض سلوك التتمر (من إعداد الباحثة). r-مقياس التتمر إعداد (مجدي محمد الدسوقي( 7 ( • ب).

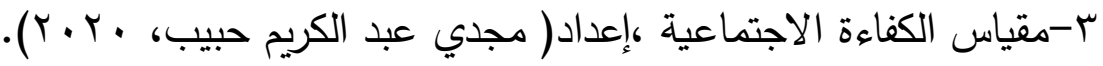

الإطار النظري

نظرا لأهمية إيجاد حلول للكثير من المشكلات التربوية للطلاب ليحدث بذلك تكيف نفسي ،وكفاءة اجتماعية في جميع المراحل من الطفولة إلى المراهقة .هناك العديد من المشكلات التي تحدث في الخفاء، وتؤثر سلباً على أبنائنا الطلاب.

ومن هذه المشكلات سلوك التتمر (الاستقواء) وهذا السلوك يؤثر على الطالب في جميع المجالات ويؤدي أيضا إلى تدني الكفاءة الاجتماعية ومن هنا أصبح من الضروري عمل مزيد من الدراسات لتحسين الكفاءة الاجتماعية وخفض سلوك التتمر لدى الطلاب من خلال برامج تدربية تحد من السلوكيات الخطر وتعدل من السلوك.

تناولت الدراسة في هذا الفصل الإطار النظري لمفاهيم الدراسة في أربعة محاور رئيسية، وهي: المحور الأول :التتمر المدرسي( مفهومه، الأسباب والعوامل التي تسهم في التتمر، الأشكال، الخصائص، الآثار المترتبة عليه)، والمحور الثاني : الكفاءة الاجتماعية( تعريفها، مفهومها ، أبعادها، أهميتها). والمحور الثالث: البرنامج التدريبي( تعريفه ، أهدافه، أنثطة الفن التشكيلي كوسيلة تشخيصية وعلاجية، النظريات المستخدمة )، المحور الرابع : مرحلة المراهقة( الأهمية ، الخصائص، الأشكال والعوامل)، وذلك من خلال

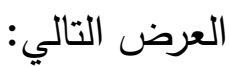


School Bullying المحور الأول: التنمر المدرسي

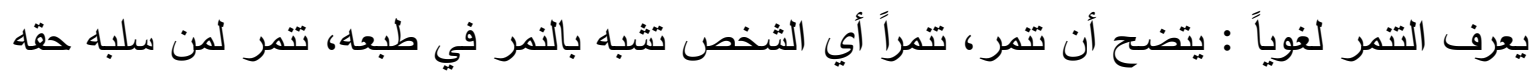

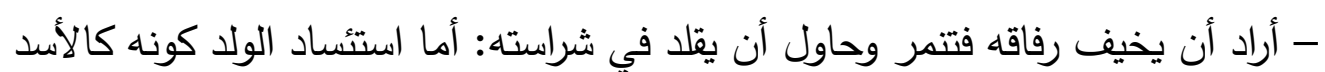

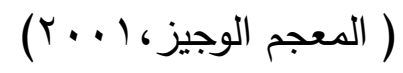

واصطلاحياً: يتضح أن ترجمة مصطلح Bullying إلى التتمر أو الاستئساد ظهر في ترجمة قدمتها رابيه

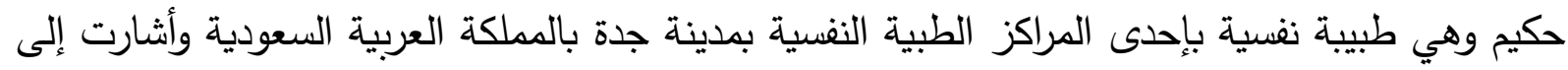

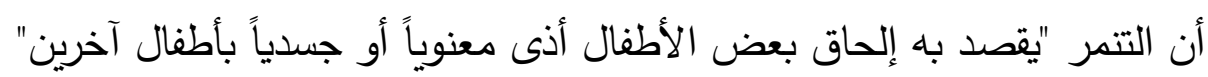

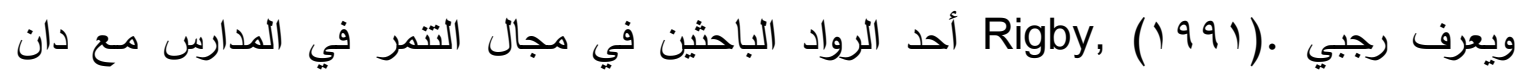

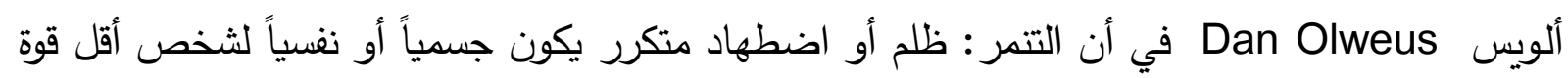
من جانب شخص أكثر قوة أو مجموعة من الأشخاص. ويختلف الظلم الذي يحدث في التتمر عن غيره من أنواع الظلم الأخرى في أن التتمر ناتج عن عدم توازن في القوة بين المتتمر والضحية، بالإضافة إلى شرط تكرار الظلم أو الاضطهاد.

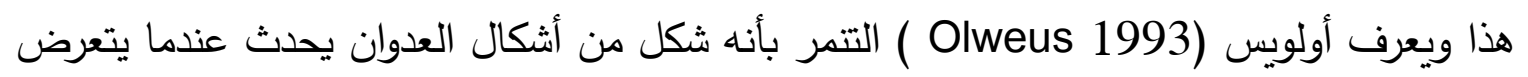

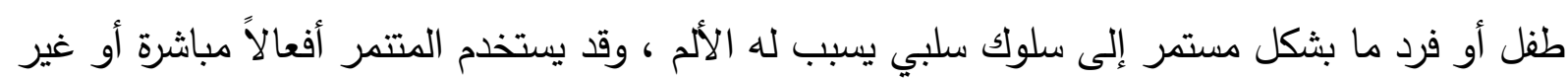

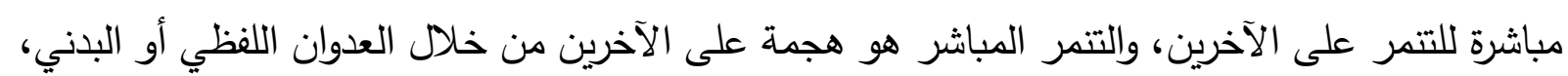

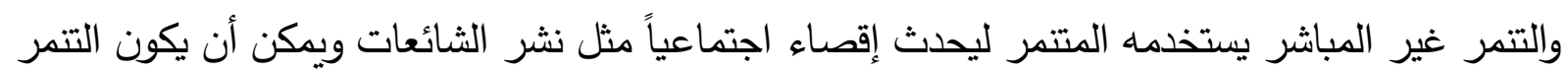
غير المباشر ضاراً جداً كالمباشر تماماً. مفهوم سلوك التنمر يُعتبر أولويس (Olweus,1993) من أوائل من درسوا الاستقواء عام 19v1 في النرويج، ويعرف

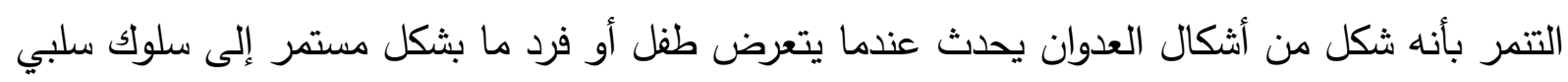

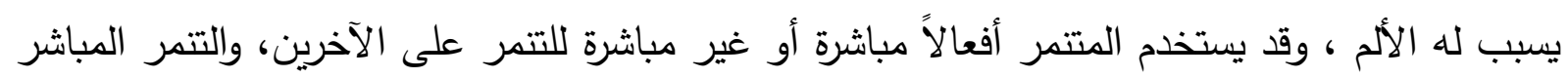
هو هجمة لهابل على الآخرين من خلال العدوان اللفظي أو البدني، والتتمر غير المباشر يستخدمه المتنمر ليحدث إقصاء

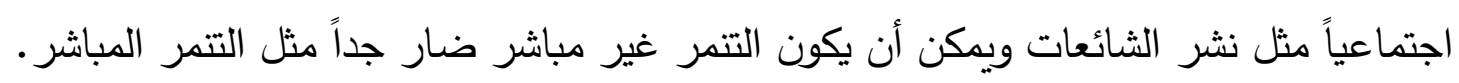

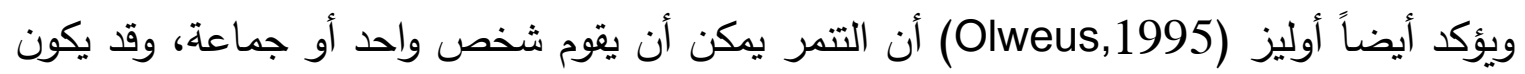

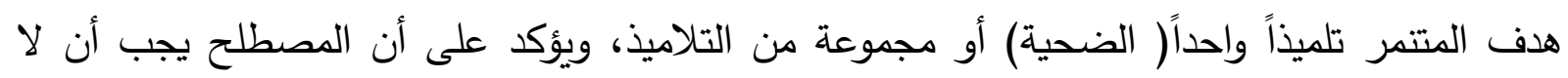

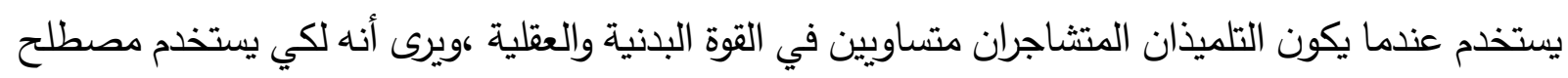
التتمر يجب أن يكون هنالك عدم توازن في القوة بين المتتمر والمتنَمر عليه. 
ويؤكد بدويل (Bidwell,1997) على أن التتمر يحدث داخل المدرسة وخارجها إلا أن الذي يقع داخل

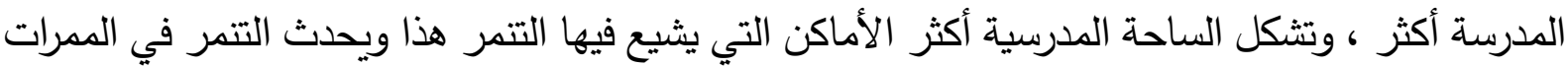
والغرف الصفية وفسحة الددرسة وأثناء انتظار الحافلات أو داخل حافلة المدرسة ويختار المتتمرين ضحاياهم من طلبة في نفس العمر أو أصغر منهم سناً. ويعرف ببلر . Cragi,(2000 \& Pepler ) التتمر على أنه شكل من أشكال العدوان لا يوجد فيه توازن للقوى بين المتنمر والضحية ودائما ما يكون المتنمر أقوى من الضحية، والتتمر قد يكون لفظياً أو لتون بدنياً أو نفسياً وقد يكون مباشر أو غير مباشر. وعرفه كاري ( Carey ملى أنه طريقة للحصول على الاهتمام من خلال ترهيب وتخويف الضحية أو بدافع الغيرة. النظريات المفسرة لسلوك التنمر أولا: نظرية التعلم الاجتماعي يُعد باندورا Bandura، وولترز Walters وباترسون Patterson وغيرهم من العلماء الذين يطلق

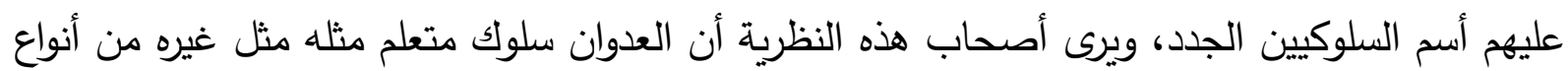

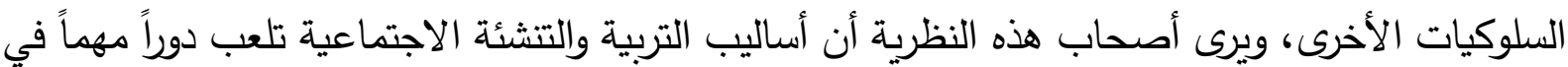
تعلم الأفراد الأساليب السلوكية التي يتمكنون عن طريقها من تحقيق أهدافهم، كما يرى أصحاب هذه النظرية

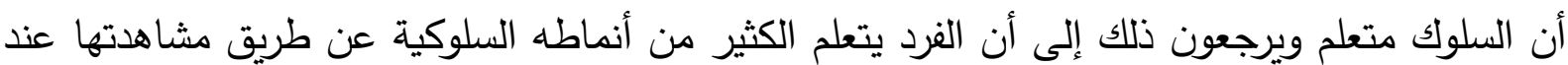

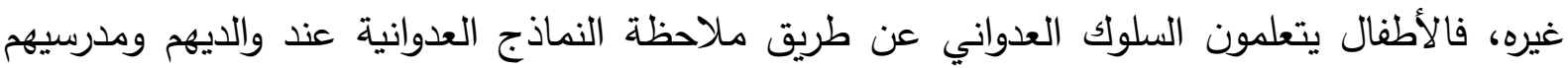

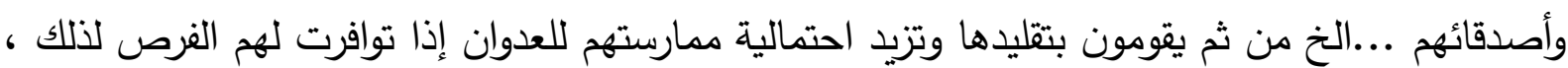
وإذا عوقب الطفل على السلوك المقلد فإنه لا يميل إلى تقليده في المرات اللاحقة أما إذا كوفئ عليه فسوف يزداد عدد مرات تقليده لهذا السلوك العدواني، ويميز أصحاب هذه النظرية بين اكتساب الفرد للسلوك وتأديته

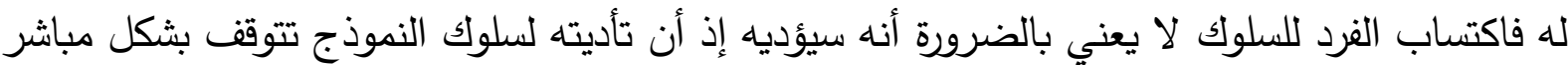
على توقعاته من نتائج التقليد وعلى نتائج السلوك، فإذا توقع أن تقليده لسلوك النموذج سيعود عليه بنتائج سلبية بمعنى أنه سيعاقب على سلوكه فإنه لا يميل إلى تقليده لهذا السلوك، أما إذا توقع الفرد أن تقليده

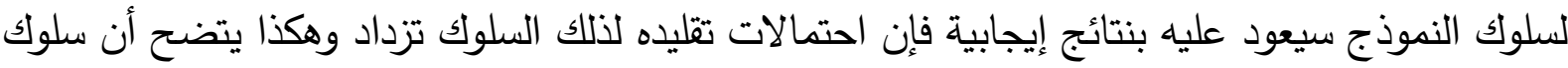

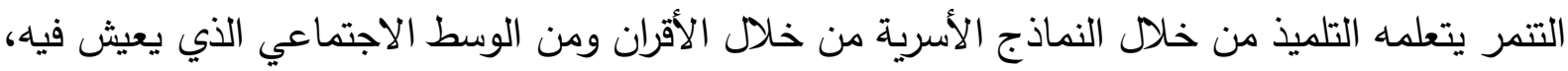

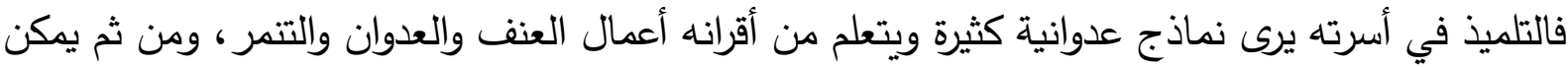

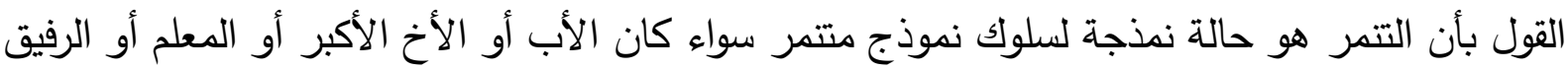
في منطقة الجيرة السكنية. 


\section{Social competence الكفاءة الاجتماعية}

الكفاءة الاجتماعية هي الأساس الذي تبنى عليه التوقعات للتفاعل المستقبلي مع الآخرين، وعلى الأفراد الذين يتم تطوير تصوراتهم السلوكية وهي أيضا مهارة تكيف مهمة يجب أن يكتسبها الأطفال والكبار لكي يعيشوا بسعادة في المجتمع، وعلى وجه الخصوص ينبغي تعليم المراهقين لفهم الصراعات المحتملة مع الآخرين، وتعلم مجموعة من استراتيجيات التفاوض بين الأشخاص لاستخدامها مع الأقران البالغين. وتثير (أماني عبد المقصود،ی . . r).إلى أن الكفاءة الاجتماعية قدرة الفرد على التعامل بنجاح مع المثيرات البيئية المختلفة المحيطة به، والقدرة على مواجهة متطلبات العمل ومدى إمكانية الفرد على تحقيق هذه المتطلبات مما يؤهله لأن يكون فرد فعال منتجاً وكفواً في تعامله مع الآخرين في المواقف الاجتماعية المختلفة، وبما ينطوي على ذلك من درجة مرتفعة من الثعور بالمسئولية الاجتماعية الاستقلالية، وصولاً إلى درجة مناسبة من الثعور بالرضا عن الذات والحياة. وقد (عرفها مجدي حبيب، • ·. ·). بأنها درجة إحساس الفرد بالارتياح في المواقف الاجتماعية، واستعداده للاشتراك في الأعمال والأنشطة الاجتماعية، واستعداده لبذل كل جهد لتحقيق الرضا في العلاقات الاجتماعية، والاندماج جيدا داخل المجموعة، والثعور بالثقة تجاه السلوك الاجتماعي، وتحقيق توازن مستمر بين الفرد وبيئته الاجتماعية لإشباع الحاجات الشخصية والاجتماعية. وعلى ذلك؛ فالكفاءة الاجتماعية هي ذلك النسق من المبادئ والتركيبات والمعرفة الذي يضع الإنسان على أهبة الاستعداد والسلوك الاجتماعي المتكامل من خلال الأعمال والأنشطة. ويشمل هذا النسق على مجموعة من المهارات المركبة والأنماط السلوكية والمعارف التي يمكن أن تظهر في السلوك الاجتماعي. إذن هي نتاج للعلاقات الديناميكية الصادرة عن تفاعل الإنسان بمهاراته الاجتماعية وميوله وحاجاته وحوافزه واتجاهاته نحو العمل الاجتماعي مع إمكانيات البيئة التي تؤثر بدورها في استعداد الإنسان للأعمال والأنشطة الاجتماعية. ثالثا : محور البرنامـج التدربي القائم على الفن التشكيلي وهو عبارة عن مجموعة من الأنشطة ( الرسم- التلوين - القص واللصق الكولاج- أنشطة تشكيل الورقالتشكيل بالصلصال - الأنشطة اليدوية- تحليل أعمال فنية - نمذجة لبعض لوحات لمشاهير الفن - ديكوباج - عجائن من الورق- طباعة- تصميم )التي يمكن استخدامها وتوظيفها بأسلوب منظم يستهدف تحقيق أغراض تتموية ونفسية عن طريق استخدام الوسائط والمواد الفنية في أنشطة فردية، وجماعية، وذلك لخفض سلوك التنمر لطلاب المرحلة الثانوية. ويؤكد ( Hrrite,W(1980 أن مستخدمو الفن كأسلوب علاجي وضعوا له قدراً كبيراً من الأهمية على عملية التخيل على أساس أنها نوع من التفكير القبل لفظي حيث يأخذ التفكير صورة تخيلات ، فالتخيلات 
تلعب دوراً كبيراً في تشكيل الشخصية المبكر وهي عنصر أساسي للظاهرة اللاشعورية، ففي العلاج بالفن تخييل للخبرات والأحلام يجعلها تأخذ صورة تخيلية بدلا من أن تترجم إلى كلمات في العلاج اللفظي البحت، فالفن وسيلة اتصال غير مألوفة وأقل قابلية للضبط والتحكم حيث أن هنالك أشياء غير متوقعة يمكن أن تبرز وتظهر في العمل الفني دون قصد مبدعها. كم أن الثخص يرتبط بالعمل الفني أكثر من ارتباطه بالذات، ويتوحد معه ويدرك انفعاله واضطرابه الخاص وبذلك لا يمثل التعبير الفني جسداً فالفرد ينفصل عن بن مشاعره لكنه يدرك بقاءها حيث تصبح المشاعر جزعاً من الذات. تثير عايدة عبد الحميد( • 99 () أن العلاج بالفن يحقق الصحة النفسية للطلاب كما أنه يتطلب ويعتمد على إلمام المعالج بمعلومات عن مراحل النمو، وبعض النظريات النفسية، وأيضا معلومات كافية عن بعض وسائل العلاج مثل زيادة الوعي بالذات، ونمو المهارات الاجتماعية والتحكم السلوكي، وحل المشكلات وتوقف القلق.

كما ترى الجمعية الأمريكية للعلاج بالفن( American Art Therapy Association AATA

أن العلاج بالفن يشبه كثيراً حصص التربية الفنية، إلا أن هناك اختلافات بينهما، وهي إنه في العلاج بالفن تكون الممارسات أهم من العمل الفني ..لأن الهدف ليس عمل فني جميل أو تشكيلا للموهبة إنما هو لمساعدة الطلاب بالثعور الجيد تجاه نغسه ومساعدته للتواصل مع الآخرين ويعرف كمال عبد الرحمن فرج (Y I r) المعالجة بالفن إلى أن مستخدمي أسلوب العلاج بالفن يركزون على العلاقة القوية بين المعاني والأبعاد اللاشعورية للرسوم والأشكال، وبين الرموز المتضمنة في التعبير الفني، والعلاج النفسي قائم على قاعدة أساسية عريضة في استخدام الفن كأسلوب تشخيصي وعلاجي وهي قبول الاستجابات و النواتج الإبداعية والفنية بصرف النظر عن مسألة الجودة الفنية.

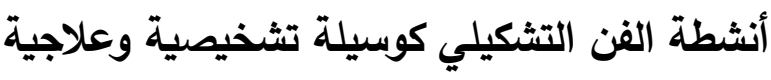
وكما يرى (عبد المطلب القريطى، ج99 ( ) بأن برامج العلاج بالأنشطة الفنية قد نشأت لمقابلة الاحتياجات الخاصة لأفراد معينين كالمرضى النفسيين، وذوي الاضطرابات الانفعالية والمعوقين وكذلك الأطفال؛ حيث إن الفن التثكيلي هو اللغة التعبيرية الانفعالية من خلاله يعبر الثخص عما يدور في ذاته من مشاعر نحو الآخرين، ويظهر ذلك في التشكيل الفني بأنواعه من خلال الإسقاط والتواصل غير اللفظي واللفظي كما اتضح الدور التنموي للانفعالات لدى أفراد عينة الدراسة وذلك من خلال التعبير عن سعادتهم بأداء الأنشطة التشكيلية بنجاح والدور الايجابي في تنمية النواحي الانفعالية لدى الطلاب المتنمرين.

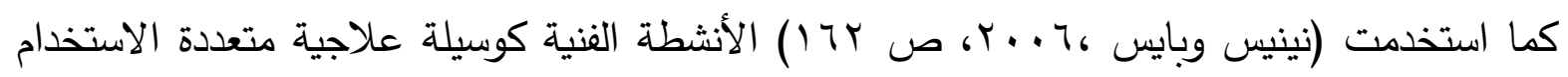
فهي ذات فائدة للعديد من المرضى المصابين بأمراض عضوية أو ذوي الإعاقات الجسمية أو النفسية أو 
العقلية أو كبار السن مما استدعى لوجود برامج تعتمد على الأنشطة الفنية في إعادة تأهيل هؤلاء الأفراد ذوي الاضطرابات الانفعالية أو المعاقين.

مروة جمعة (Y (Y. أن استخدام الأنشطة الفنية كوسائط تشخيصية وعلاجية نشأت على إيدي المعالجون بالفن Art therapists ، الذين سعوا للمساهمة في تقويم كثير من الحالات العادية وغير العادية( النفسية- العقلية- العضوية- السلوكية)، وذلك بتوظيف وسائط الفن التشكيلي وأدواته لإعادة تهيئة الطفل غير العادي ودمجه في الحياة العامة. تعريف الباحثة الاجرائي: مجموعة من الأنشطة الفنية التشكيلية التي يمارسها الطلاب وتثتمل على) الرسم، والتصوير، والنحت، والطباعة، والأشغال ،والنقد والتحليل ،والتصميم) وذلك لتفريخ طاقاتهم الزائدة ويتيح لهم التعبير عما بداخلهم مما يساعدهم على إيجاد علاقة اتصالية بين الفرد والعمل التشكيلي ومن ثم يتسع نطاق الاتصال ليمتد إلى الأقران والبيئة المحيطة مما يترتب عليه تتمية التعاون، كسر حاجز العزلة بينه وبين زملائه مما يعدل كثير من السلوكيات كالتتمر والعدوان وبالتالي يحسن الكفاءة الاجتماعية.

النظريات المفسرة لدور الفن في خفض سلوك التنمر نظرية التحليل النفسي التي تفسر دور الفن في خفض التنمر تعد هذه النظرية هي النظرية النفسية الأكثر تأثيرا في مجالات الفنون والنقد وقد كان تأثيرها المبكر في المدرسة السريالية واضحا لدرجة أن ناقدا مثل هربرت ريد يقول : (إنني أشك في أن السريالية كان يمكن أن توجد في صورتها الراهنة لولا سيجموند فرويد، فهو المؤس الحقيقي للمدرسة، فكما يجد فرويد مفتاحا لتشابكات الحياة وتعقيداتها في مادة الأحلام، فكذلك يجد الفنان السريالي خير إلهام لله في المجال نفسه، إنه لا يقدم مجرد ترجمة مصورة لأحلامه، بل إن هدفه هو استخدام أي وسيلة ممكنة تمكنه من النفاذ إلى يلى محتويات اللاشعور المكبوتة، ثم يخرج هذه العناصر حسبما يتراءى له بالصورة الأقرب إلى الوعي، وأيضا

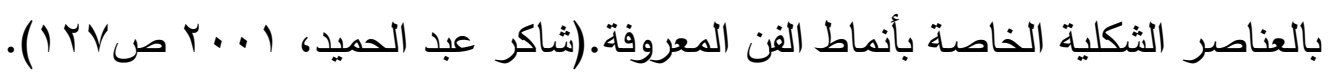
وتأثير التحليل النفسي في السريالية - مثلا - واضح في حديث الفنانين، وفي اهتمامهم بتسجيل صور الأحلام، واهتمامهم كذلك بحالات الهذيان والتداعي الحر والهالاوس والجنون. أكد فرويد في تفسيره للإدراك، أو التذوق في مجال الفنون، على أن مصادر المتعة التي يحصل عليها المتلقي للعمل إنما تكمن في اللاشعور، فالفن في رأيه يقدم للمتلقي incentive bonus an أي حافزا إضافيا، بمعنى أنه يسمح لمتلقيه بالاستمتاع بمادة قد تكون مهددة للأنا أو ضارة بها، لو قدمت بشكل أخر أكثر مباشرة، وأن المرء يكون كذلك غير واع بمصادر المتعة، وأسبابها التي يحصل عليها من تلقيه ،أو تأمله للعمل الفني. 
يحتل اللاشعور مكانة محورية في هذا المنحى التحليلي النفسي واللاشعور هو وحدة أو هوية دينامية

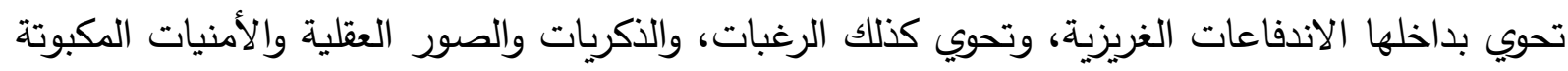
وغير الواقعية، وهو مصدر أساسي للإبداع والتذوق الفني بشكل عام في ضوء ما تراه ولاه هذه النظرية. البرامج التدريبي

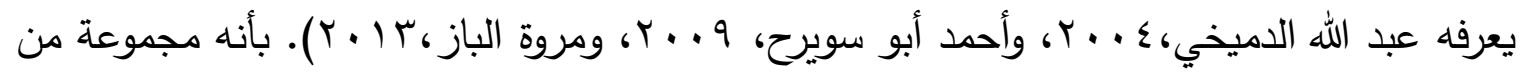
الأنثطة التدريبية البناءة التي تساعد الفرد على الكثف عن مشكلاته ، وفهم ذاته، وتتمية إمكانياته، وتشمل سلسلة من الخبرات والأنثطة والأساليب التدريبية المتنوعة والمنظمة ، تهدف إلى تحسين وتعديل سلوك الفرد بهدف تغير اتجاهاتهم للأفضل وصقل مهاراتهم ورفع كفاءتهم. ويتضح من التعريفات السابقة أن البرامج التدريبية هي برامج موجهة توجيهاً معرفياً، أي أنها تستند

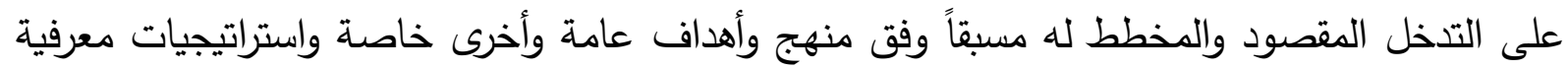
وانفعالية وممارسات تربوية، ليكتب الفرد المهارات المستهدفة للبرنامج.

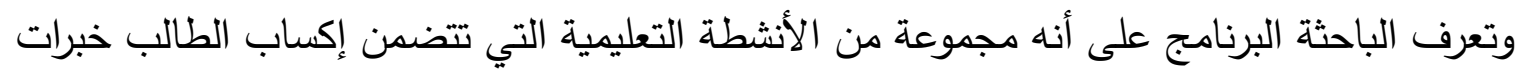

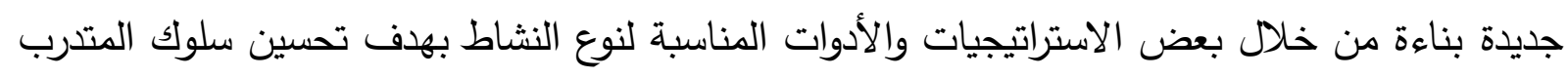
ورفع كفاءته الاجتماعية. أسس البرنامج

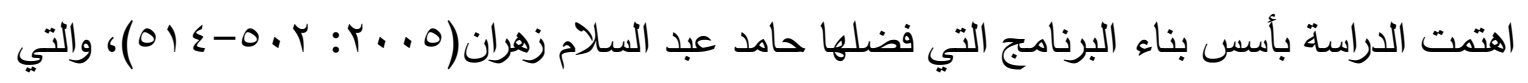

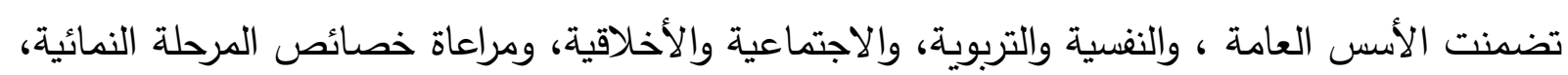

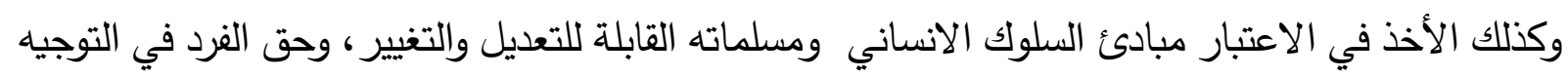

$$
\text { أولاً: الأرشاد وتقرير المصير . }
$$

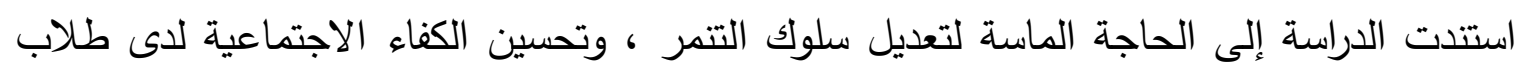

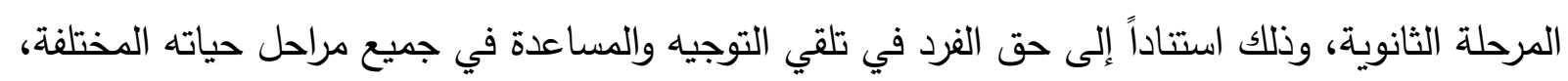

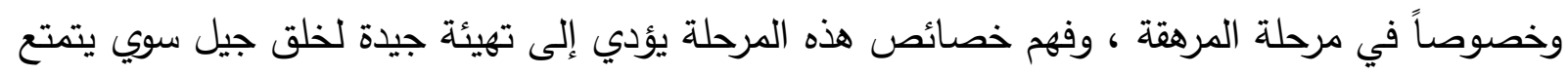
بالصحة النفسية، وبالتالي يمكن له أن يتكيف مع المجتمع بكافة أشكاله. ثانياً: الأسس الفلسفية انطلاقا من نظرية التعلم الاجتماعي لباندورا وتأكيدها على أن الملاحظة للبيئة الخارجية سبب من التبان

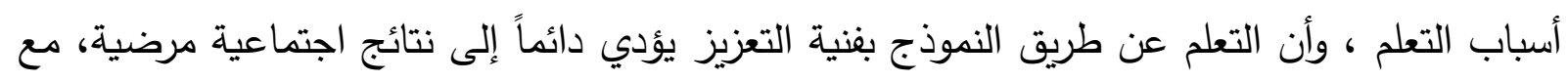
مراعاة طبيعة وخصائص المرحلة والهذف من البرنامج. 
ثالثاً: الأسس النفسية

اهتمت الدراسة بأهمية المرحلة العمرية التي يمر بها طلاب المرحلة الثانوية، وما تحتاجه من دعم تربوي يرفع من قدرم العلمي ، لوجود فئة من الطلاب تحتاج إلى خدمات تربوية، مما لذلك من أهمية في تحديد مسار حياتهم إلى الأفضل، وتحسين الكفاءة الاجتماعية لديهم ، وشعورهم أنهم أشخاص فاعلين في المجتمع مما يجعلهم في المستقبل قادرين على أخذ القرارات بشكل صحيح يتناسب مع قدراتهم. رابعاً: الأسس التربوية

اهتمت الدراسة بأن تكون أهداف البرنامج بأنواعها متوافقة مع أهداف العملية التربوية، كما استخدمت الفنيات المناسبة لتحقيق الأهداف في كل تدريب ، لكي تساهم في تحسين الأداء الأكاديمي والنفسي للطلاب ، من خلال الأنشطة والتدريبات التي تغير سلوكيات الطلاب ومعلوماتهم وأفكارهم إلى الأفضل دائماً. خامساً :الأسس الاجتماعية نظراً لدور الجماعة المؤثر في سلوكيات الفرد سواء كان مضطرب سلوكياً أو من الأسوياء اهتمت الدراسة بتوظيف بعض الاستراتيجيات و الفنيات في البرنامج التدربي، التي من خلالها تقوي العلاقات الاجتماعية بين الفرد والجماعة كالمناقثات الجماعية حول عمل فني أو من خلال العمل بروح الفريق من بن خلال الأعمال الفردية المجمعة في عمل واحد وذلك يهيئ جو من التقبل للأقران بعضهم البعض ويحسن من الكفاءة الاجتماعية لديهم ومن ثم في البيئة الاجتماعية المحيطة.

مصادر البرنامج

اعتمدت الدراسة على بعض المصادر في إعداد البرنامج التدربي كالإطار النظري الذي يلقي الضوء على متغيرات الدراسة، والدراسات السابقة العربية والأجنبية التي تتاولت البرامج التدرببية وكذا التي تعلتت بنفس مجال الدراسة، كما كان للمؤتمرات والكتب والدوريات والمجلات والمقاييس دوراً فعال في إعداد

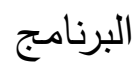
دراسات سابقة أولاً: محور الدراسات التي تتاولت التتمر المدرسي

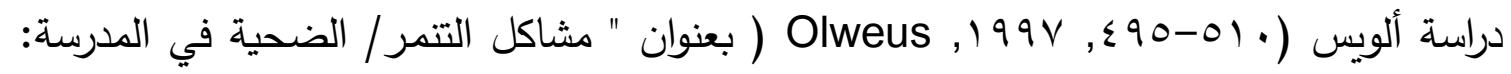
الحقائق ووسائل التخخل "، وكان الهدف منها تقييم آثار برنامج التخخل الذي يهدف إلى تقليل مشاكل المتنمر / الضحية الموجودة على قدر الإمكان ومنع نشوء مشاكل جديدة. وأوضحت الدراسة بعض الحقائق المهمة وهي مجموعة من المبادئ الأساسية التي يقوم عليها البرنامج والتي تسعى إلى تطوير وتعديل مشاكل السلوك محل الاهتمام، وخاصة السلوك العدواني، وخلق بيئة مدرسية تتميز بالدفه والاهتمامات الإيجابية وتدخل البالغين من جهة. 
وحدود صارمة للسلوك غير المقبول من جهة أخرى وفي حالة انتهاك هذه الحدود والقواعد يجب تطبيق عقوبات غير معادية وغير جسدية بشكل متسق. كما ينطوي المبدآن الآخران على درجة من المراقبة والإشراف على أنشطة الطلاب داخل وخارج المدرسة وعلى الكبار في المدرسة والمنزل أن يتصرفوا بشكل سلطوي على الأقل في بعض الحالات. وبالنسبة لتقييم

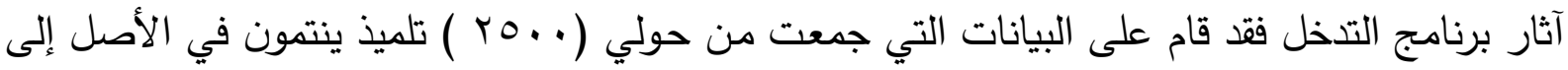

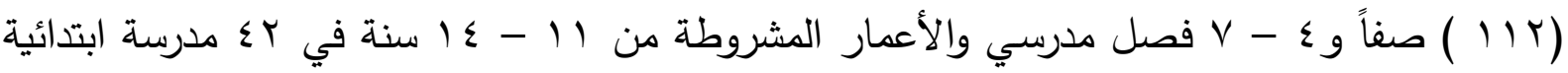
وثانوية في بيرجن في النرويج •

ولقد تم تتبع التلاميذ الخاضعين للدراسة على مدى سنتين ونصف من عام سم19 1910 وحتى 190 وخلصت النتائج الأساسية للتحاليل إلى التالي:

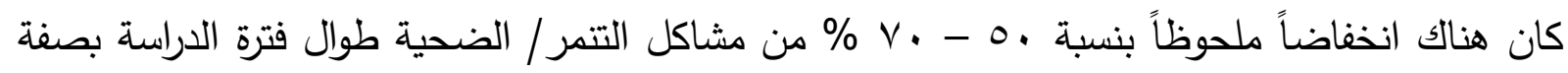
عامة و هذا الانخفاض حدث لكل من التتمر المباشر حيث يتعرض لهجوم صريح نسبياً، والتنمر غير المباشر حيث يعزل الضحية ويستبعد من الجماعة. وانطبقت النتائج بصفة عامة على كل من الفتيان والفتيات والتلاميذ من جميع الصفوف التي خضعت للدراسة.

لم يحدث تغيير في مشاكل المتنمر / الضحية في الطريق من وإلى المدرسة كان هناك تحسن واضح وملحوظ خاص بالجوانب المختلفة للمناخ الاجتماعي بالفصل، تحسن في النظام والانضباط، وعلاقات اجتماعية أكثر إيجابية، ومواقف أكثر إيجابية تجاه الواجبات المدرسية وفي ذات الوقت فقد زاد ارتياح التلاميذ بالحياة المدرسية لم يؤثر برنامج التدخل فقط على مشاكل الإيذاء الموجودة بالفعل بل أنه قلل من عدد ونسبة الضحايا الجدد وبذلك، فقد كان للبرنامج نتائج وقاية أولية وثانوية. بصفة عامة، خلصت الدراسة إلى أن التغيرات في مشاكل المتنمر / الضحية وأنماط السلوك حدثت على الأرجح نتيجة لبرنامج التتخل وليست بسبب عوامل أخرى ذات صلة. وتأتي دراسة وودز وآخرون (Woods, et al.,2007) فقد اهتمت بدراسة الفروق بين الجنسين في تقديرهم لسلوك التتمر من خلال الرسوم المتحركة رواشتملت عينة الدراسة على (•^) طالب وطالبة من المدارس الابتدائية حيث قدمت لهم قصصاً مصورة ورسومات متحركة مصحوبة باستبانة تركزت أسئلتها على تقدير درجة التعاطف مع الشخصيات في القصص والرسوم ،وقد أظهرت النتائج اختلافات جوهرية بين الجنسين حيث أظهرت الإناث تعاطفاً وفهماً لضحايا التنمر أما الذكور فكانوا أكثر تقصصاً وتقليداً لسلوك 
شخصيات المتمرين، وأوصت الدراسة بأن يؤخذ في الاعتبار جنس الطفل عند تصميم شخصيات الرسوم المتحركة والسيناريوهات التي تشارك فيها.

الميل للنشاط الزائد ، وفي سلوك إيذاء الذات، وفي السلوك الانسحابي لصالح المجموعة التجريبية. ثانياً: محور الدراسات التي تناولت الكفاءة الاجتماعية أشارت دراسة نعيمة الرفاعي وحنان الضرغامى (11 (1) فاعلية برنامج تدخل معرفي سلوكي قائم على الضبط الذاتي في تحسين الكفاءة الاجتماعية وخفض السلوك المعادي للمجتمع لدى عينة في مرحلة المراهقة المتأخرة، وتكونت العينة من ( • ع) تلميذا من تلاميذ المرحلة الإعدادية بمدرستين من إدارة سرس الليان التعليمية (الشهيد الجندي بنين ومدرسة الإعدادية بنات) وتكونت العينة من(Y Y) تلميذاً و(1 ( ) تلميذة، استخدمت الباحثتان الأدوات التالية: مقياس (merrell,1993) لقياس الكفاءة الاجتماعية والسلوك المعادي للمجتمع لأفراد العينة - البرنامج المعرفي السلوكي المستخدم • وأسفرت نتائج الدراسة إلى وجود فروق دالة إحصائياً بين متوسطات درجات العينة على مقياس الكفاءة الاجتماعية قبل وبعد تطبيق البرنامج لصالح التطبيق البعدي وذلك يدل على فاعلية البرنامج المعرفي السلوكي في تحسين الكفاءة الاجتماعية لدى عينة في مرحلة المراهقة.

ثالثاً: محور الاراسات التي تناولت دور الفن التثكيلي في تعديل السلوك. هدفت دراسة حنان حسن نشأت( 99 ( ) التحقق من فاعلية الفن التشكيلي في تعديل سلوك الأطفال المتخلفين عقليا ، تكونت عينة الدراسة من (ب0) طفلا من الذكور والإناث من مدارس التربية الفكرية، تتراوح أعمارهم الزمنية بين (7-0 (1) سنة، استخدمت أدوات لجمع البيانات منها : مقياس سلوك التوافق (A.B.C) ( الطباعة ، القص واللصق، العجائن) وقد أسفرت نتائج الدراسة عن نجاح برنامج الفن التشكيلي في توجيه العدوان لموقف آخر تسمح لظهوره ولكن بطريقة لا عدوانية، وكذلك تعديل أنماط السلوك التالية: العنف والسلوك التدميري، السلوك غير المؤتمن، السلوك النمطي، العادات الغربة، السلوك المتمرد ، الانسحاب، سلوك اجتماعي غير مناسب، الميل للنشاط الزائد. في حين تناولت ميلاد إبراهيم متى(ع . . ب) التي هدفت إلى تتمية مهارات الأطفال المعاقين عقليا القابلين للتعلم اللازمة للتعبير الفني من خلال الفنون الحديثة، تكونت العينة من( • ب) طفلا وطفلة من

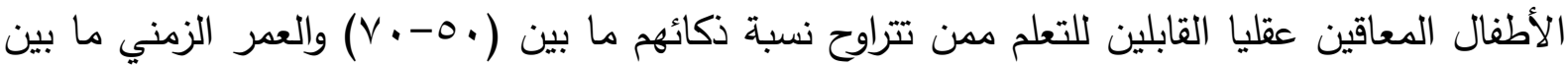
(9- ( ) سنة، وقد أشارت نتائج الدراسة إلى نمو قدرة الأطفال المعاقين عقليا القابلين للتعلم على التعبير 
الفني بالاستفادة من الفنون الحديثة، كما أظهرت النتائج ميل الأطفال إلى التجريب بالخامات والأدوات التي طرحتها الفنون الحديثة.

منهج الاراسة

اعتمدت هذه الدراسة على المنهج شبه التجريبي ذو المجموعة الواحدة( القياس القبلي ثم البعدي ثم التتبعي) بعد مرور فترة زمنية( شهرين)، بهدف الكثف عن فعالية برنامج تدربي قائم على الفن التشكيلي في خفض السلوك التتمري وتحسين الكفاءة الاجتماعية لدى طلاب المرحلة الثانوية. - المتغير المستقل: برنامج تدريبي قائم على الفن التشكيلي. - المتغير التابع : السلوك التنمري - الكفاءة الاجتماعية.

مجتمع الاراسة

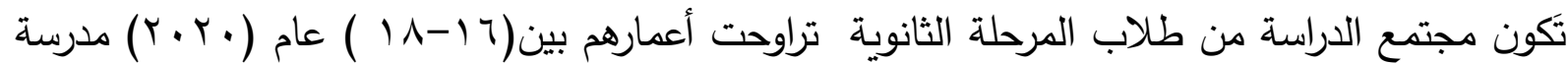
النجاح الثانوية المشتركة بمحافظة البحيرة. عينة الدراسة

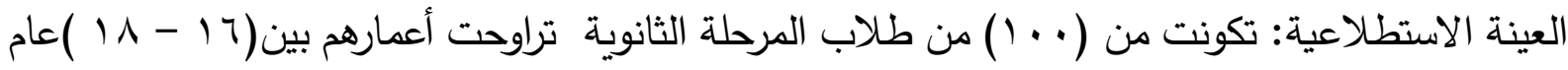

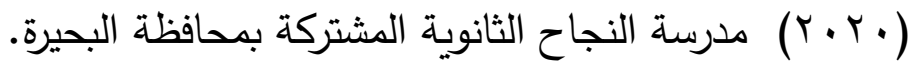
ب - العينة الاساسية : تكونت العينة الأساسية من (ro) من طلاب الصف الأول الثانوي تراوحت أعمارهم بين (7 ا-1 1 ) ، تمثل مجموعة تجريبية تلقت التدريب من خلال برنامج تدريبي قائم على الفن التشكيلي في خفض السلوك التتمري وتحسين الكفاءة الاجتماعية لدى طلاب المرحلة الثانوية . أدوات الدراسة

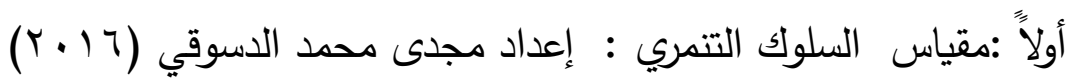

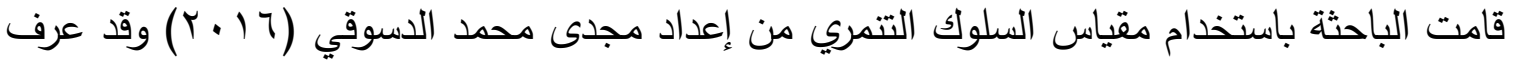
مُعد الأداة السلوك التنمري بأنه: سلوك سلبي مقصود يتصف بالديمومة والاستمرارية من جانب المتنمر لإلحاق الأذى بفرد آخر ( الضحية أو المتتمر به) ، وتكون الأفعال السلبية لفظية أو جسمية أو نفسية أو بادئ اجتماعية بهدف إيذائه أو مضايقته أو عزله عن المجموعة واستبعاده من الأنشطة الجماعية، ويشترط لحدوث هذا السلوك عدم التوازن في القوة بين المتنمر والضحية( علاقة قوة غير متماثلة) أي صعوبة الدفاع عن النفس. 
التحقق من الخصائص السيكومترية للمقياس

قامت الباحثة بتطبيق المقياس على عينة التقنين المكونة من ( · . ( ) من طلاب المرحلة الثانوية ، وقد تم اختيارهم بثكل عشوائي من مدارس محافظة البحيرة وذلك لحساب صدق وثبات المقياس ، وفيما

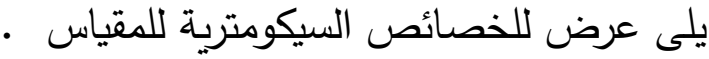
أ- الصدق: صدق الاتساق الداخلي :

تم حساب صدق الاتساق الداخلي ( على عبارات المقياس وعددها . ؛ عبارة ) باستخدام معامل ارتباط بيرسون وذلك عن طريق استخراج معامل ارتباط درجة كل عبارة بدرجة البعد الذى تتتمى إليه - بعد حذف درجة العبارة من درجة البعد - وبالدرجة الكلية بعد حذف درجة العبارة من الدرجة الكلية باعتبار باقي العبارات محكاً للعبارة ، والجدول ( 1 ) يوضح ذلك . جدول (1)

معاملات الارتباط بين درجات عبارات البعد الأول والدرجة الكلية للمقياس (ن= . . )

\begin{tabular}{|c|c|c|c|c|c|}
\hline ru & 1 & رقم العبارة & رu & נر & رقم العبارة \\
\hline $0.432 * *$ & $0.475 * *$ & 33 & $0.587 *$ & $0.574 * *$ & 24 \\
\hline $0.497 * *$ & $0.607^{*} *$ & 38 & $0.619 * *$ & $0.550 * *$ & 25 \\
\hline $0.654 *$ & $0.457 * *$ & 8 & $0.642 * *$ & $0.485 * *$ & 2 \\
\hline $0.430 * *$ & $0.539 * *$ & 3 & $0.571 *$ & $0.529 * *$ & 21 \\
\hline $0.587 * *$ & $0.493 * *$ & 7 & $0.592 * *$ & $0.628 * *$ & 16 \\
\hline $0.435 *$ & $0.532 * *$ & 6 & $0.574 * *$ & $0.707 * *$ & 17 \\
\hline $0.455 * *$ & $0.514^{* *}$ & 10 & $0.565 * *$ & $0.541 * *$ & 30 \\
\hline
\end{tabular}

ر ا تثير إلى معامل ارتباط درجة العبارة بدرجة البعد ر r تشير إلى معامل ارتباط درجة العبارة بالدرجة الكلية

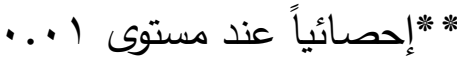
*إحصائياً عند مستوى 0 ... يتضح من الجدول ( ) أن جميع عبارات البعد الأول من مقياس السلوك التمري لها علاقة ارتباطية ذات دلالة إحصائية بدرجة البعد الأول وبالدرجة الكلية للمقياس ـ مما يعنى أن العبارات تثترك في قياس التنمر النفسي من السلوك التنمري لدى طلاب المرحلة الثانوية . 


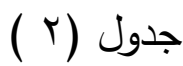

صدق الاتساق الداخلي لمقياس السلوك التنمري (معاملات الارتباط بين درجات عبارات البعد الثاني

$$
\text { والدرجة الكلية للمقياس) (ن= ( . ( ) }
$$

\begin{tabular}{|c|c|c|c|c|c|}
\hline رu & 1 & رقم العبارة & ru & \multicolumn{2}{|c|}{ رقم العبارة ر ر } \\
\hline $0.458 * *$ & $0.497 * *$ & 23 & $0.642 * *$ & $0.465^{* *}$ & 5 \\
\hline $0.642 * *$ & $0.627 * *$ & 39 & $0.508^{* * *}$ & 0.580 ** & 1 \\
\hline $0.475^{* *} *$ & $0.518 * *$ & 20 & $0.593 * *$ & $0.645^{* *}$ & 15 \\
\hline $0.551 * *$ & $0.559 * *$ & 12 & $0.741 * *$ & $0.566^{* * *}$ & 9 \\
\hline $0.632 * *$ & $0.508 * *$ & 19 & 0.631 ** & $0.669 * *$ & 32 \\
\hline $0.593 * *$ & $0.477 * *$ & 11 & $0.422 * *$ & 0.584 ** & 40 \\
\hline & & & $0.741^{* *}$ & $0.654 * *$ & 36 \\
\hline
\end{tabular}

ر ا تثير إلى معامل ارتباط درجة العبارة بدرجة البعد ر ץ تثير إلى معامل ارتباط درجة العبارة بالدرجة الكلية

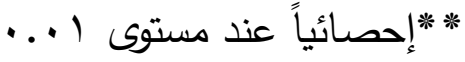
"إحصائياً عند مستوى ه...

يتضح من الجدول( r ) أن كل عبارات البعد الثاني من مقياس السلوك التتمري لها لها

علاقة ارتباطية ذات دلالة إحصائية بدرجة البعد الثاني وبالدرجة الكلية للمقياس ، مما يعنى أن العبارات تشترك في قياس التتمر اللفظي للدى طلاب المرحلة الثانوية .

$$
\text { جدول (r ) }
$$

صدق الاتساق الداخلي لمقياس السلوك التتمري ( معاملات الارتباط بين درجات عبارات البعد الثالث

\begin{tabular}{|c|c|c|c|c|c|}
\hline رu & 1ر & |رقم العبارة & ru & ر & رقم العبارة \\
\hline $0.490 * *$ & $0.669 * *$ & 14 & $0.425^{* *}$ & $0.366 * *$ & 13 \\
\hline $0.485 * *$ & $0.584 * *$ & 4 & $0.452 * *$ & $0.390 * *$ & 27 \\
\hline \multirow[t]{2}{*}{$0.524 * *$} & $0.497 * *$ & 35 & $0.618 * *$ & $0.654 * *$ & 18 \\
\hline & & & $0.374 * *$ & $0.546 * *$ & 31 \\
\hline
\end{tabular}

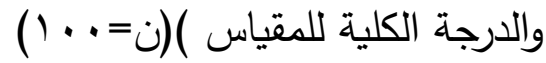

ر ا تشير إلى معامل ارتباط درجة العبارة بدرجة البعد 
ر r تشير إلى معامل ارتباط درجة العبارة بالدرجة الكلية

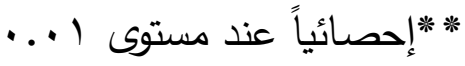
إحصائياً عند مستوى 0 ... يتضح من الجدول ( r ) أن كل عبارات البعد الثالث من مقياس السلوك التتمري لها علاقة ارتباطية ذات دلالة إحصائية بدرجة البعد الثالث وبالدرجة الكلية للمقياس ـ مما يعنى أن العبارات تثترك في قياس التنمر الاجتماعي للى طلاب المرحلة الثانوية .

$$
\text { جدول (飞) }
$$

صدق الاتساق الداخلي لمقياس السلوك التتمري ( معاملات الارتباط بين درجات عبارات البعد الرابع والدرجة الكلية للمقياس )(ن= . ( )

\begin{tabular}{|c|c|c|c|c|c|}
\hline ru & 1 & رقم العبارة & ر & 1 & رقم العبارة \\
\hline $0.529 *$ & $0.657 * *$ & 29 & $0.474 * *$ & $0.634 * *$ & 26 \\
\hline $0.528 * *$ & $0.475 * *$ & 28 & $0.565 * *$ & $0.733 * *$ & 22 \\
\hline $0.458 * *$ & $0.462 * *$ & 37 & $0.718 * *$ & $0.811 * *$ & 34 \\
\hline
\end{tabular}

ر ا تثير إلى معامل ارتباط درجة العبارة بدرجة البعد ر ب تشير إلى معامل ارتباط درجة العبارة بالدرجة الكلية

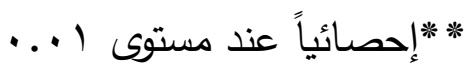

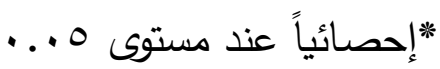
يتضح من الجدول ( ع ) أن كل عبارات البعد الرابع من مقياس السلوك التمري لها علاقة ارتباطية ذات دلالة إحصائية بدرجة البعد الرابع وبالدرجة الكلية للمقياس ـ مما يعنى أن العبارات تشترك في قياس التنمر الجسمي لاى طلاب المرحلة الثانويـة كما تم استخراج معامل ارتباط درجة كل بُعد بدرجة الأبعاد الأخرى والدرجة الكلية للمقياس والجدول رقم

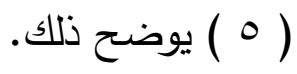

$$
\text { جدول (o) }
$$

\begin{tabular}{|c|c|c|c|c|c|}
\hline الدرجة الكلية & الجسمري & الإجتمر & التنمر & التنمر & الأبعاد \\
\hline $0.895 *$ & $0.795 \% *$ & $0.580 * *$ & $0.708 * *$ & & التتمر النفسي \\
\hline $0.911 * *$ & $0.712^{* *}$ & $* * 0.740$ & & & التنمر اللفظي \\
\hline
\end{tabular}

علاقة الأبعاد ببعضها وبالدرجة الكلية لمقياس السلوك التنمري لطلاب المرحلة الثانوية (ن=. . 1) 


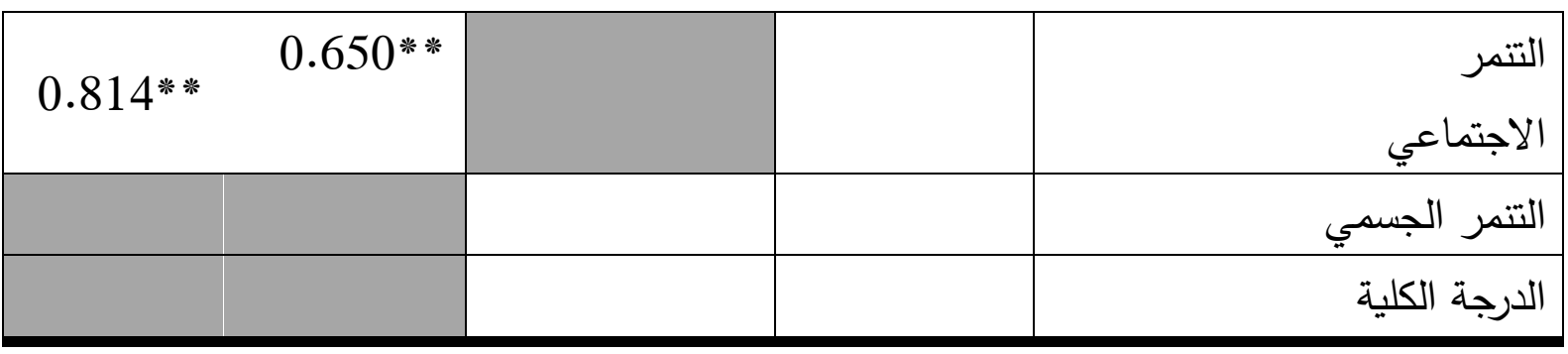

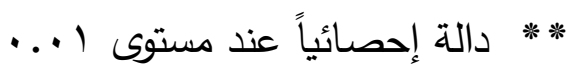

*دالة إحصائياً عند مستوى 0 . .. .

يتضح من الجدول أن جميع أبعاد مقياس السلوك التنمري لطلاب المرحلة الثانوية ترتبط فيما بينها عند مستوى دلالة (1 . . .) وهذا يدل على صدق الاتساق الداخلي للأبعاد مع الدرجة الكلية للمقياس. ب- الثبات:

قامت الباحثة بحساب الثبات مقياس السلوك التتمري باستخدام طريقة سبيرمان براون وجتمان للتجزئة النصفية ومعامل ألفا كرونباخ ، والجدول ( 7 ) يوضح معامل الثبات بالطرق الثلاثة لمقياس •

$$
\text { جدول (1 ) }
$$

معاملات ثبات مقياس السلوك التتمري

\begin{tabular}{|c|c|c|c|c|}
\hline التجزئة الثبات بطريقة ألفا & الثبات بطريقة & الثبات $\quad$ بطيريقة & عدد & أبعاد المقياس \\
\hline 0.805 & 0.847 & 0.854 & 14 & التنمر النفسي \\
\hline 0.787 & 0.775 & 0.783 & 13 & التتمر اللفظي \\
\hline 0.785 & 0.730 & 0.779 & 7 & التتمر \\
\hline 0.718 & 0.785 & 0.782 & 6 & التتمر الجسمي \\
\hline 0.924 & 0.868 & 0.878 & 40 & الدرجة الكلية \\
\hline
\end{tabular}

يتبين من الجدول السابق ( 1 ) أن مقياس السلوك التتمري يتمتع بدرجات عالية من الثبات وأبعاده المختلفة، مما يشير إلى الوثوق بنتائج المقياس على عينة الدراسة الحالية . الصورة النهائية لمقياس السلوك التنمري : والجدول التالي يوضح لمقياس السلوك التنمري جدول (V) ) عدد عبارات مقياس السلوك التنمري وتصحيح.

\begin{tabular}{|c|c|c|}
\hline مدى الدرجات & عدد العبارات & المقياس \\
\hline $14-70$ & 14 & التنمر النفسي \\
\hline
\end{tabular}




\begin{tabular}{|c|c|c|}
\hline $13-65$ & 13 & التتمر اللفظي \\
\hline $7-35$ & 7 & التتمر الاجتماعي \\
\hline $6-30$ & 6 & التنمر الجسمي \\
\hline $40-200$ & $1-40$ & السلوك التتمري \\
\hline
\end{tabular}

النتائج المتعلقة بالفرض الأول

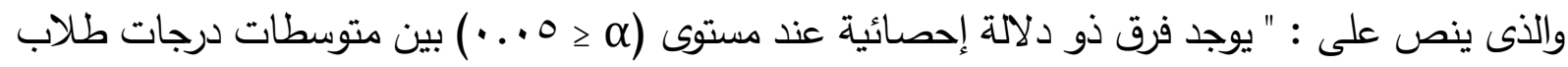
المجموعة التجريبية على مقياس السلوك التمري في القياسين القبلي و البعدي لصالح القياس البعدي. ويتفرع من هذا الفرض الرئيس الفروض الفرعية التالية :

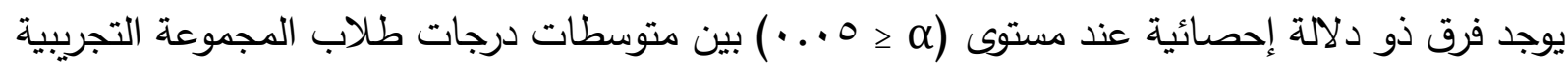
على مقياس السلوك التتمري في القياسين القبلي و البعدي على بُعد التتمر النفسي لصالح القياس البعدي.

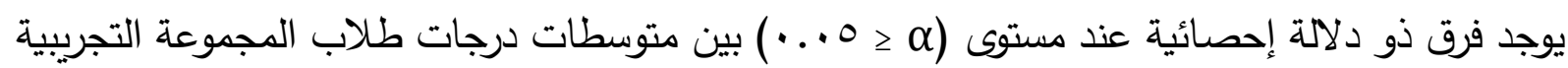
على مقياس السلوك التنمري في القياسين القبلي و البعدي على بُعد التتمر اللفظي لصالح القياس البعدي دوني

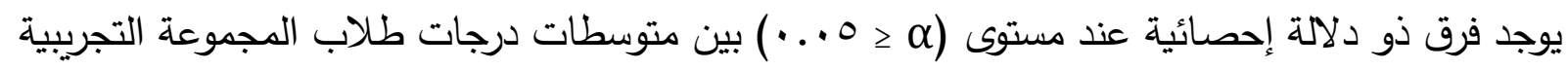

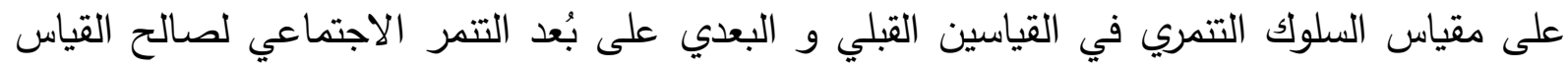

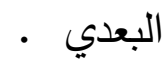

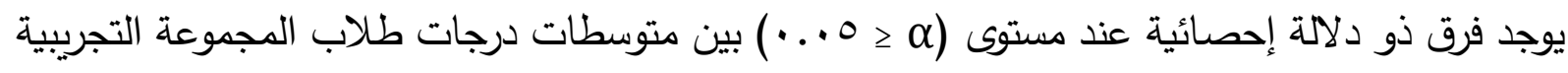
على مقياس السلوك التتمري في القياسين القبلي والبعدي على مستوى الدرجة الكلية لصالح القياس البعدي. وللتحقق من صحة هذا الفرض وفروضه الفرعية قامت الباحثة بمقارنة متوسطات درجات طلاب المجموعة التجريبية في القياسين القبلي والبعدي ، وذلك لمقياس السلوك التتمري. وقد استخدمت الباحثة اختبار "ت (للمجموعات المرتبطة Paired- Samples t Test للكثف عن دلالة الفرق بين المتوسطات باستخدام برنامج SPS .v21 ويوضح الجدول التالي (ع ا ( ) ) تلك النتائج: 


$$
\text { جدول ( } 1 \text { ( ) ( ل) }
$$

المتوسطات والانحرافات المعيارية وقيم " ت " لدرجات طلاب المجموعة التجربية في القياسين القبلي والبعدي لمقياس السلوك التنمري

\begin{tabular}{|c|c|c|c|c|c|c|c|}
\hline مستوى الدلالة & قيمة & درجة الحرية & الانحراف المعياري & المتوسط & العدد & القياس & الأبعاد \\
\hline$\ldots 1$ & $r \varepsilon . \wedge r$ & r $\varepsilon$ & $\begin{array}{l}\varepsilon . V 1 \\
\text { r. VV }\end{array}$ & $\begin{array}{l}0 \text {. } \\
\text { ro.07. }\end{array}$ & $\begin{array}{l}\text { ro } \\
\text { ro }\end{array}$ & البقلي البعدي & التة \\
\hline. .1 & rی.Y & Y $\varepsilon$ & $\begin{array}{l}\text { r. } \\
\text { E.r. }\end{array}$ & $\begin{array}{l}\varepsilon q . \vee r \\
\text { r.. . }\end{array}$ & $\begin{array}{l}\text { ro } \\
\text { ro }\end{array}$ & القبلي البعدي & \\
\hline. .1 & Yo.. o & $r \varepsilon$ & $\begin{array}{l}r .71 \\
r .11\end{array}$ & 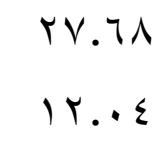 & $\begin{array}{l}\text { ro } \\
\text { ro }\end{array}$ & البقلي البعدي & هاعي \\
\hline. .1 & $\mid 1 . .1$ & r $\varepsilon$ & $\begin{array}{l}\text { r. . } \\
\text { r.VY }\end{array}$ & 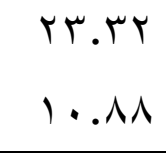 & $\begin{array}{l}\text { ro } \\
\text { ro }\end{array}$ & الببلي البعدي & \\
\hline. .1 & $r . \varepsilon r$ & Y $\varepsilon$ & $\begin{array}{l}V .0 V \\
1 . .1 .\end{array}$ & $\begin{array}{l}10 \varepsilon .0 Y \\
V I . \Lambda \Lambda\end{array}$ & $\begin{array}{l}\text { ro } \\
\text { ro }\end{array}$ & القبلي البعدي & الدرجة الكلية \\
\hline
\end{tabular}

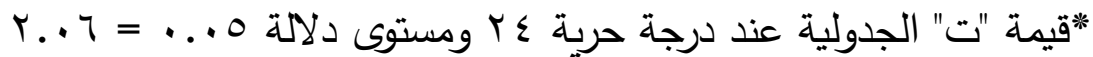

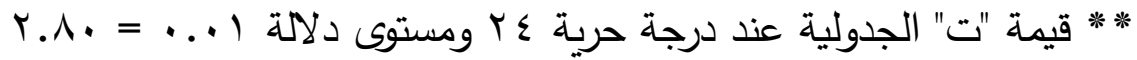
يتضح من الجدول السابق ما يلى: أنه بمقارنة متوسطات درجات طلاب المجموعة التجريبية للقياسين القبلي والبعدي لمقياس السلوك التتمري ، لوحظ أن متوسط القياس البعدي أقل من القبلي، وقد أرجعت الباحثة ذلك إلى استخدام برنامج تدريبي قائم على الفن التشكيلي للمجموعة التجريبية أن قيم (ت) دالة احصائيا عند مستوى دلالة (1 . . ) بين متوسطي درجات المجموعة التجريبية للقياسين القبلي والبعدي في مقياس السلوك التتمري • ولذا تم قبول الفرض الاول وفروضه الفرعية الذى ينص على : يوجد فرق ذو دلالة إحصائية عند مستوى (1 ...) بين متوسطات درجات طلاب المجموعة التجرببية لمقياس السلوك التنمري في القياسين القبلي والبعدي لصالح القياس البعدي( (ى الاتجاه الأفضل ). وفروضه 
وترى الباحثة منطقية هذا الفرض حيث يؤكد ذلك على نجاح وفعالية البرنامج التدربي المستخدم ، حيث يرجع سبب نجاح البرنامج التدريبي إلى استخدام مجموعة من التدريبات المناسبة للمرحلة واستخدامها لأسلوب التعزيز المستمر •

وتتفق هذه النتيجة مع نتائج دراسات كل من : ( كمال عبد الرحمن فرج، ب ( ب) في فاعلية العلاج بالفن التشكيلي في خفض بعض الاضطرابات السلوكية كالعدوان والتتمر ، وأيضاً مع دراسة ( ماكيني، ج . . ؟)، وهناك العديد من الدراسات التي تؤكد منطقية الفرض الأول مثل دراسة( ندا نصر الدين غريب،م ( • ب)، (استورس وارنر Storch Masia,2003) ، (كلير فوكس وميثيل بولتون،ه . . ب). النتائج المتعلقة بالفرض الثاني

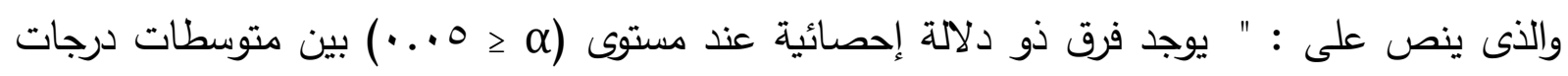
طلاب المجموعة التجريبية على مقياس الكفاءة الاجتماعية في القياسين القبلي و البعدي لصالح القياس البعدي.

وللتحقق من صحة هذا الفرض قامت الباحثة بمقارنة متوسطات درجات طلاب المجموعة التجريبية في القياسين القبلي والبعدي ، وذلك لمقياس الكفاءة الاجتماعية وقد استخدمت الباحثة اختبار "ت" ل للمجموعات المرتبطة Paired- Samples t Test للكشف عن دلالة الفرق بين المتوسطات باستخدام برنامج SPS .v21) ويوضح الجدول التالي ( 10 ) متلك النتائج : جدول (17)

المتوسطات والانحرافات المعيارية وقيم " ت " لدرجات طلاب المجموعة التجربية في القياسين القبلي والبعدي لمقياس الكفاعة الاجتماعية .

\begin{tabular}{|c|c|c|c|c|c|c|c|}
\hline الدلالة & قيمة ت & درجة & الالمعياري & المتوسط & العدد & القياس & المقياس \\
\hline$\cdots 1$ & $1 . .91$ & $r \varepsilon$ & $\begin{array}{l}\varepsilon . \Gamma . \\
\text { Y.A. }\end{array}$ & $\begin{array}{l}19.87 \\
1.17\end{array}$ & $\begin{array}{l}\text { ro } \\
\text { ro }\end{array}$ & البعلي البعدي & الكفاءة \\
\hline
\end{tabular}

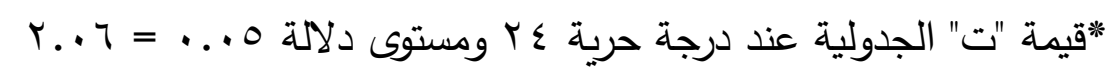

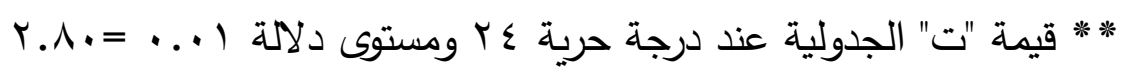
يتضح من الجدول السابق ما يلى:

أنه بمقارنة متوسطات درجات طلاب المجموعة التجربية لقياسين القبلي والبعدي لمقياس الكفاءة الاجتماعية ، لوحظ أن متوسط القياس البعدي أكبر من القبلي، وقد أرجعت الباحثة ذلك إلى استخدام برنامج تدريبي قائم على الفن التشكيلي للمجموعة التجربيية 
أن قيم (ت) دالة احصائيا عند مستوى دلالة ( ( . . ) بين متوسطي درجات المجموعة التجريبية للقياسين القبلي والبعدي في مقياس الكفاءة الاجتماعية. ولذا تم قبول الفرض الثاني الذي ينص على : يوجد فرق ذو دلالة إحصائية عند مستوى (1 ...) بين متوسطات درجات طلاب المجموعة التجربية لمقياس الكفاءة الاجتماعية في القياسين القبلي و البعدي لصالح القياس البعدي. ويمكن تفسير النتيجة السابقة بما يلي :بالرجوع إلى جدول (0) الذي يوضح الفرق بين التطبيقين القبلي والبعدي على المجموعة التجريبية في اختبار مقياس الكفاءة الاجتماعية يتضح وجود فروق بين متوسطات درجات المجموعة التجربية في التطبيق القبلي والبعدي في اختبار مقياس الكفاءة الاجتماعية. وترى الباحثة منطقية هذا الفرض حيث إن هذا الفرض اتفق مع ما توصلت إليه دراسة(محمود عكاشة ،

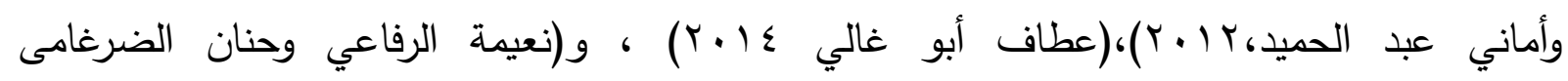

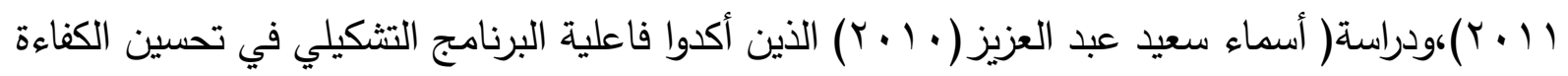
الاجتماعية لدى الطلاب في مرحلة المراهقة. حجم التأثير: استخدمت الباحثة مقياس مربع إيتا " †2" لتحديد حجم تأثير المتغير المستقل وهو : استخدام برنامج تدريبي قائم على الفن التشكيلي على المتغير التابع وهو : الكفاءة الاجتماعية وباستخدام الأساليب الإحصائية لحساب قيمتي2٪، d)). جاءت النتائج كما هي موضحة في الجدول التالي

النتائج المتعلقة بالفرض الثالث

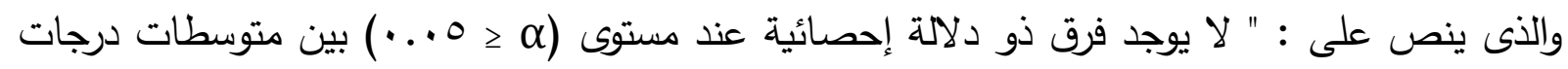
طلاب المجموعة التجريبية على مقياس السلوك التتمري في القياسين البعدي والتتبعي • ويتقرع من هذا الفرض الرئيس الفروض الفرعية التالية :

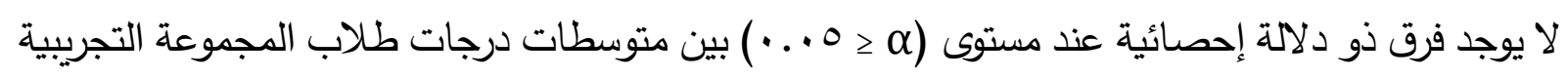

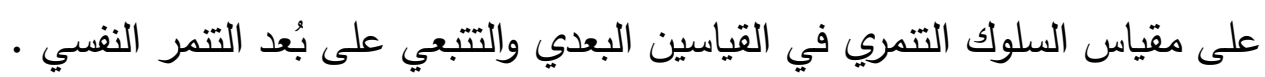

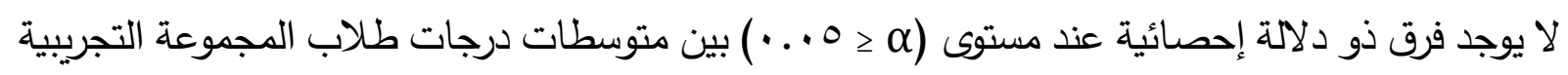
على مقياس السلوك التتمري في القياسين البعدي والتتبعي على بُعد التتمر اللفظي.

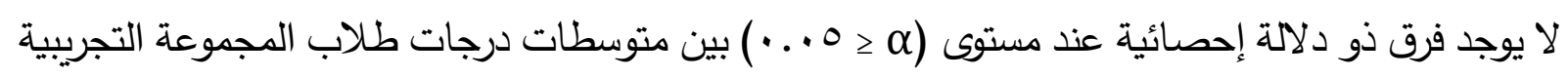
على مقياس السلوك التتمري في القياسين البعدي والتتبعي على بُعد التتمر الاجتماعي . ل

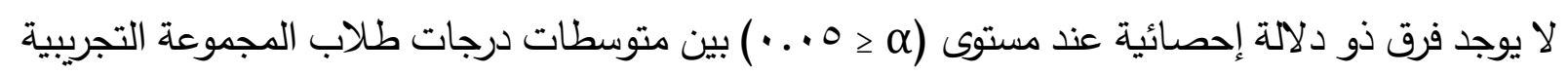
على مقياس السلوك التنمري في القياسين البعدي والتتبعي على بُعد التتمر الجسمي. 


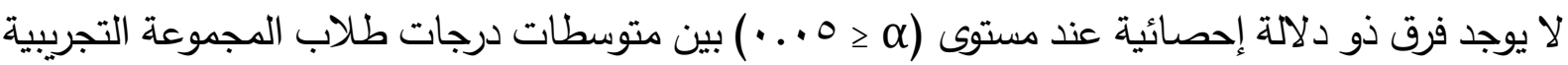
على مقياس السلوك التتمري في القياسين البعدي والتتبعي على مستوى الدرجة الكلية. وللتحقق من صحة هذا الفرض وفروضه الفرعية قامت الباحثة بمقارنة متوسطات درجات طلاب المجموعة التجرببية في القياسين البعدي والتتبعي ، وذلك لمقياس السلوك التنمري • وقد استخدمت الباحثة اختبار "ت" للمجموعات المرتبطة Paired- Samples t Test للكثف عن دلالة الفرق بين المتوسطات ( باستخدام برنامج SPSS .v21) ويوضح الجدول التالي ( IV ) تلك النتائج : جدول (11) (1)

المتوسطات والانحرافات المعيارية وقيم " ت " لدرجات طلاب المجموعة التجريبية في القياسين البعدي والتتبعي لمقياس السلوك التتمري.

\begin{tabular}{|c|c|c|c|c|c|c|c|}
\hline مستوى الدلالة & تيمة & درجة & الانحراف & المتوسط & العدد & القياس & الأبعاد \\
\hline 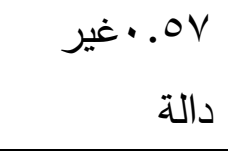 & .07 & $r \varepsilon$ & $\begin{array}{l}\text { T.TV } \\
\text { r.vi }\end{array}$ & $\begin{array}{l}\text { Y0.0T } \\
\text { Y0.E. }\end{array}$ & $\begin{array}{l}\text { ro } \\
\text { ro }\end{array}$ & البعدي التبعي & ر ر النفسر \\
\hline$\ldots 1$ & r.07 & TE & $\begin{array}{l}\varepsilon . r t \\
r .0 Y\end{array}$ & $\begin{array}{l}\text { rT.E. } \\
\text { r.or }\end{array}$ & $\begin{array}{l}\text { ro } \\
\text { ro }\end{array}$ & البعدي التبعي & اللفظي \\
\hline ـ ــ ـ • غير &.$\vee \wedge$ & $r \varepsilon$ & $\begin{array}{l}\text { r.11 } \\
r .1 .\end{array}$ & $\begin{array}{l}\text { M..E } \\
\text { M.r. }\end{array}$ & $\begin{array}{l}\text { ro } \\
\text { ro }\end{array}$ & البعدي التبعي & \\
\hline דس . •غيردالة & .94 & $r \varepsilon$ & $\begin{array}{l}r . V T \\
r . Y T\end{array}$ & $\begin{array}{l}1 . .11 \\
1 . .71\end{array}$ & $\begin{array}{l}\text { ro } \\
\text { ro }\end{array}$ & البعدي التبعي & الإجتماعر \\
\hline. .0 & Y.IV & $r \varepsilon$ & $\begin{array}{l}1 . .1 . \\
1.01\end{array}$ & $\begin{array}{l}\vee . \wedge \Lambda \\
\vee . . \Lambda .\end{array}$ & $\begin{array}{l}\text { ro } \\
\text { ro }\end{array}$ & البعدي التبعي & الكلية \\
\hline
\end{tabular}

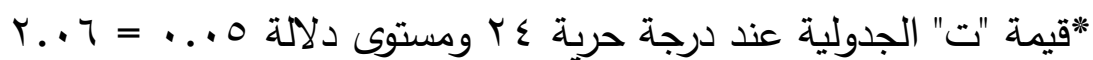

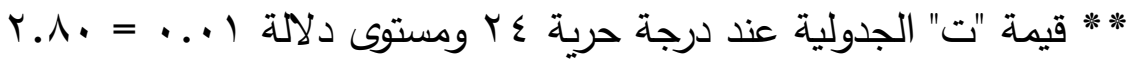
يتضح من الجدول السابق ما يلى: أنه بمقارنة متوسطات درجات طلاب المجموعة التجريبية للقياسين البعدي والتتبعي لمقياس السلوك التتمري ، لوحظ أن متوسطات القياس البعدي أكبر من متوسطات القياس التتبعي، وقد أرجعت الباحثة ذلك إلى استخدام برنامج تدريبي قائم على الفن التشكيلي للمجموعة التجريبية 
أن قيم (ت) دالة احصائيا عند مستوى دلالة ( ( . . ) بين متوسطي درجات المجموعة التجريبية للقياسين البعدي والتتبعي في مقياس السلوك التنمري في التتمر اللفظي والدرجة الكلية للسلوك التنمري. أن قيم (ت) غير دالة احصائيا عند مستوى دلالة (0...) بين متوسطي درجات المجموعة التجرببية للقياسين البعدي والتتبعي في مقياس السلوك التنمري للأبعاد التنمر النفسي والجسمي والاجتماعي.

ولذا تم رض الفرض الثالث وفروضه الفرعية جزئياً أي أن : يوجد فرق ذو دلالة إحصائية عند مستوى (1 (.+) بين متوسطات درجات طلاب المجموعة التجريبية لمقياس السلوك التنمري في القياسين البعدي والتتبعي لصالح القياس التتبعي في المقياس ككل و التتمر - اللفظي

ويمكن تفسير النتيجة السابقة بما يلي : بالرجوع للجدول (1) الذي يوضح الفروق بين التطبيق البعدي والتتبعي على المجموعة التجريبية في اختبار مقياس التتمر يتضح وجود فروق بين متوسطات درجات المجموعة التجريبية في التطبيق البعدي والتتبعي في اختبار السلوك التتمري. وترى الباحثة منطقية هذا الفرض وذلك بسبب حرص الباحثة والطلاب على تطبيق البرنامج بشغف وعدم تخلف الطلاب عن الجلسات من بداية البرنامج حتى نهايته ، كما يرجع أيضا نجاح البرنامج إلى استخدام الباحثة لاستراتيجيات وفنيات مناسبة لكل تدريب وتوفير الأدوات باستمرار وساعد ذلك على بقاء الأثر والاحتفاظ بالتحسن بعد مرور فترة المتابعة. النتائج المتعلقة بالفرض الرابع

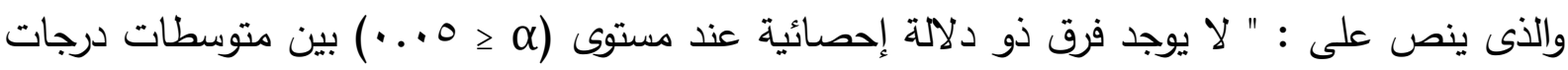
طلاب المجموعة التجربيية على مقياس الكفاءة الاجتماعية في القياسين البعدي والتتبعي وللتحقق من صحة هذا الفرض قامت الباحثة بمقارنة متوسطات درجات طلاب المجموعة التجريبية في القياسين البعدي والتتبعي ، وذلك لمقياس الكفاءة الاجتماعية وقد استخدمت الباحثة اختبار "ت" للمجموعات المرتبطة Paired- Samples t Test للكثف عن دلالة الفرق بين المتوسطات

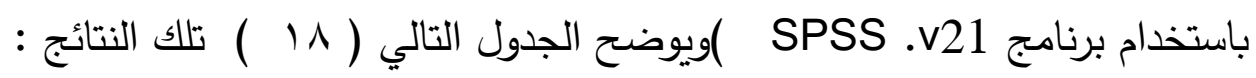




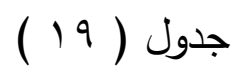

المتوسطات والانحرافات المعيارية وقيم " ت " لدرجات طلاب المجموعة التجريبية في القياسين البعدي

والتتبعي لمقياس الكفاءة الاجتماعية .

\begin{tabular}{|c|c|c|c|c|c|c|c|}
\hline الدلالة & | & الحرية & الانحراف & المتوسط & العدد & القياس & المقياس \\
\hline$\ldots 9$ & $1 . V V$ & $r \varepsilon$ & $\begin{array}{l}r . \wedge 1 \\
r .71\end{array}$ & $\begin{array}{l}r . .17 \\
r . . \leqslant \Lambda\end{array}$ & $\begin{array}{l}\text { ro } \\
\text { ro }\end{array}$ & التبعي & الكفاءة \\
\hline
\end{tabular}

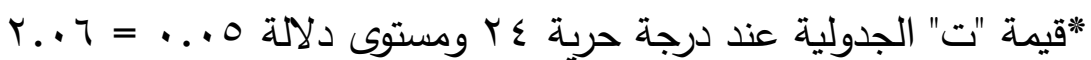

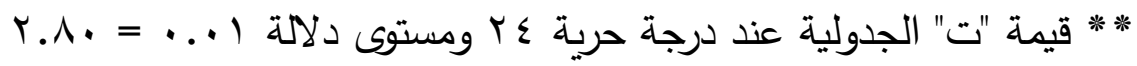

$$
\text { يتضح من الجدول السابق ما يلى: }
$$

أنه بمقارنة متوسطات درجات طلاب المجموعة التجريبية للقياسين البعدي والتتبعي لمقياس الكفاءة

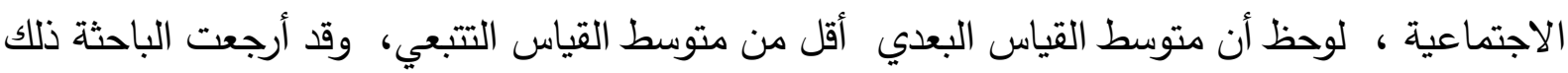
إلى استخدام برنامج تدريبي قائم على الفن التثكيلي للمجموعة التجريبية التئية

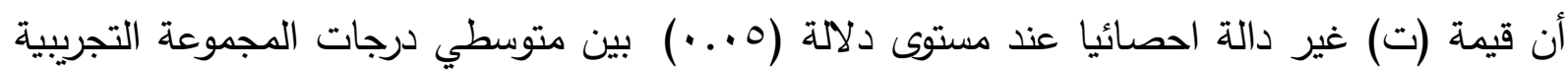

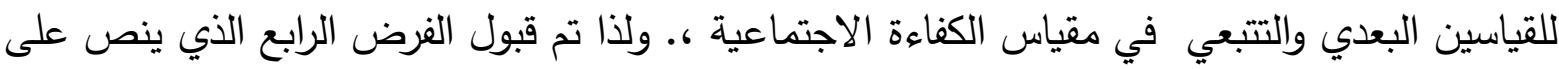
لا يوجد فرق ذو دلالة إحصائية عند مستوى (0...) بين متوسطات درجات طلاب المجموعة التجريبية

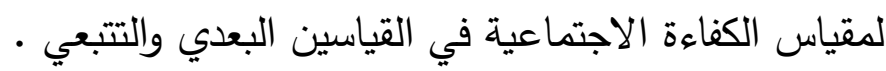

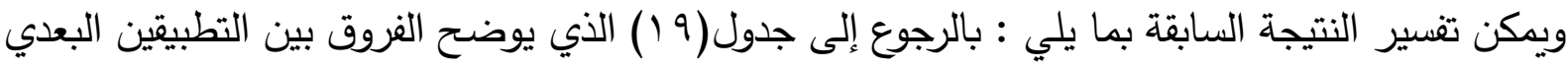

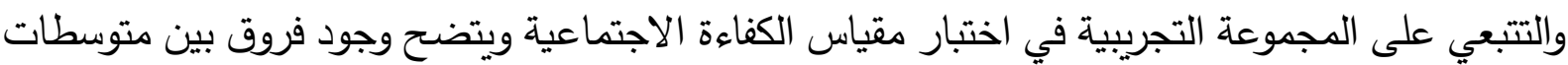
درجات المجموعة التجريبية في التطبيق البعدي والتتبعي في اختبار الكفاءة الاجتماعية

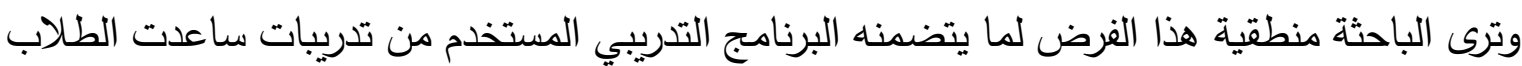

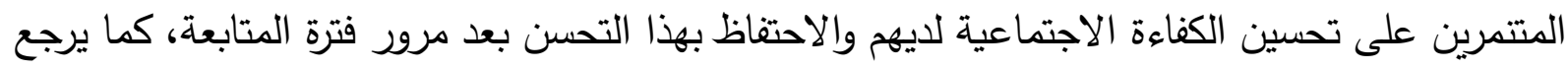
نجاح البرنامج أيضا إلى حرص الباحثة على التتوع بين جلسات البرنامج وشغف الطلاب واستمتاعهم لألئ

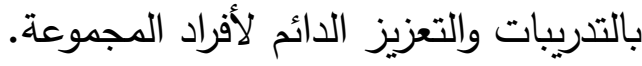




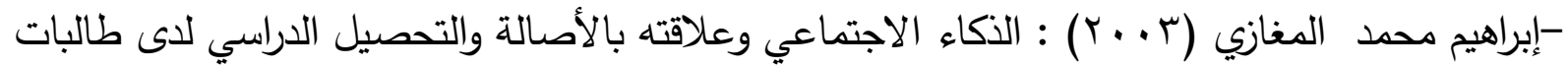
المرحلة الثانوية ، مجلة كلية التربية ، المجلد الأول ، جامعة طنطا.

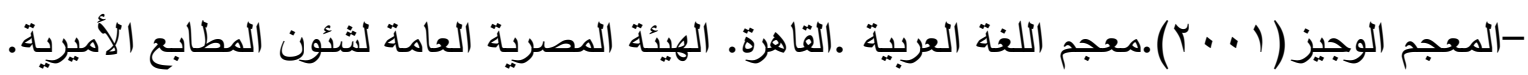
- أماني عبد المقصود(^ ـ . ؟). مقياس التفاعل الاجتماعي للأطفال. القاهرة: مكتبة الأنجلو المصرية.

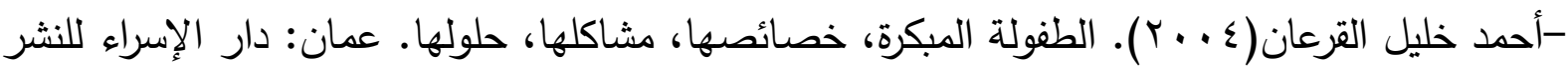
والتوزيع.

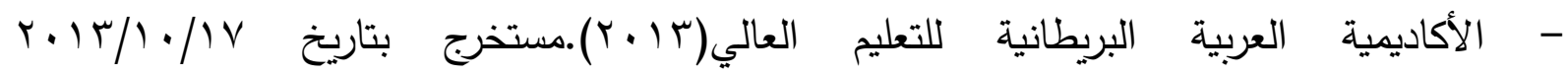

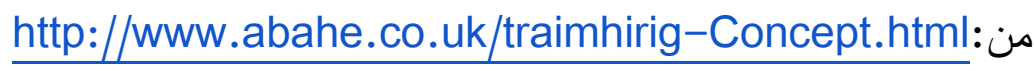

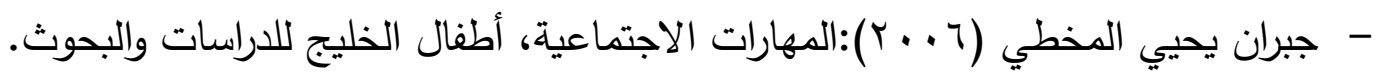

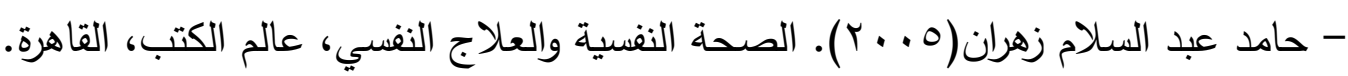

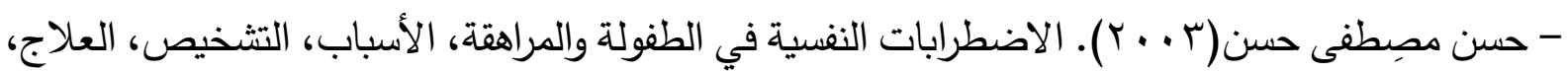

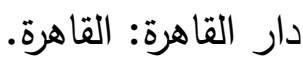
- حنان حسن نثأت (ـ991). أثر استخدام الفن التثكيلي في تعديل بعض المظاهر السلوكية لدى المتخلفين عقليا، رسالة ماجستير غير منشورة، كلية الآداب ، جامعة عين شمس.

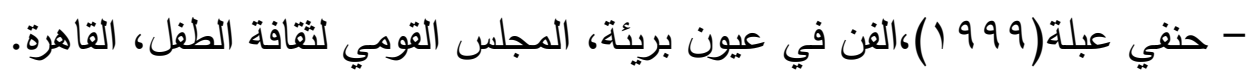

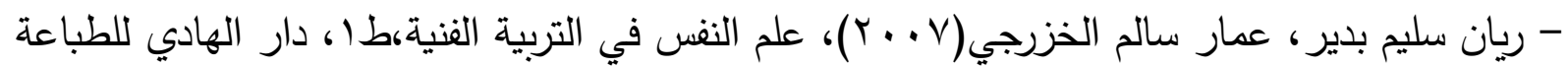

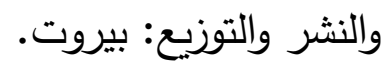
- شاكر عبد الحميد( ( . ب)،التفضيل الجمالي، دراسة في سيكولوجية التذوق الفني، المجلس الوطني للثقافة والآداب، الكويت.

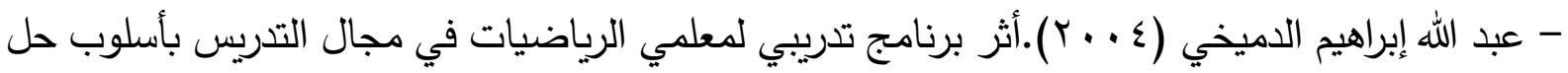
المشكلات في التحصيل الدراسي لطلاب الصف الثاني المتوسط بمدينة الرياض .رسالة ماجستير، كلية التربية، جامعة الملك سعود: الرياض. -عبد المطلب القريطى ( 997 ()،سيكولوجية ذوي الاحتياجات الخاصة وتدريبهح ، دار الفكر العربي،

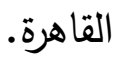
- -عايدة محمد عبد الحميد( • 99 ().العلاج بالفن مدخل نفسي تتموي لرعاية الطفل المتخلف عقلياً، مجلة

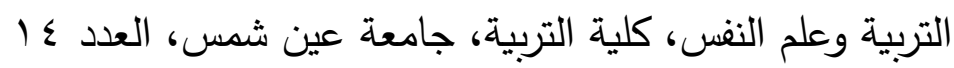


-عزت عبد الله، خيري السيد(11 (ب).المناخ الأسري كما يدركه الأبناء وعلاقته بالكفاءة الاجتماعية لدى عينة من طلاب الجامعة. مجلة كلية التربية. جامعة الأزهر . العدد(0 ـ ().00-19. - عوض مبارك سعد اليامي( • ( ب). استراتيجية مقترحة في تأهيل علاج أطفال التوحد من خلال الفن التشكيلي، بحث بمركز العلاج بالفن، الرياض. - عادل كمال خضر(999 (19).استخدام الاختبار الشخصي في التشخيص والعلاج، القاهرة: مجلة علم النفس، الهيئة المصرية العامة للكتاب، ص ص r ب-1 • 1. - علي موسى الصبحيين، محمد فرحان القضاة(ب . . r). سلوك التنمر عند الأطفال والمراهقين(مفهومهأسبابه- علاجه). الرياض: جامعة نايف العربية للعلوم الأمنية. - عصام الخليفات( • ( • (ب).تحديد الاحتياجات التدريبية لضمان فاعلية البرنامج التدربي. عمان: دار صفاء للنشر والتوزيع. - عصام عبد اللطيف العقاد( ( . +r). سيكولوجية العدوانية وترويضها منحى علاجي معرفي جديد :دار غريب ، القاهرة. - فيوليت فؤاد إبراهيم، ميلاد إبراهيم متى، نهى صلاح على(1 1 ـ ب). فاعلية برنامج قائم على التعبير الفني المجسم لقصص الأطفال في تخفيف سلوك إيذاء الذات لدى الأطفال المعاقين عقليا القابلين للتعلم، مجلة

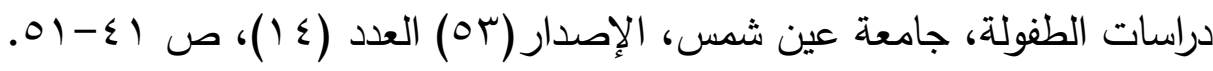

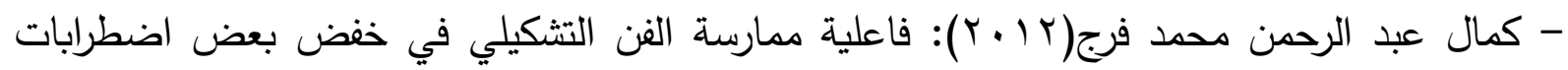

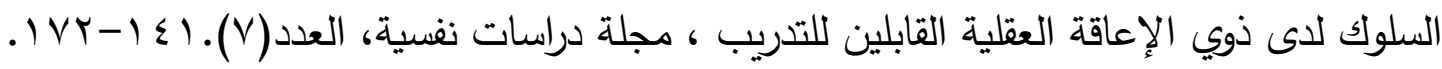
- ميلاد ابراهيم متى (ع . . ץ). برنامج مقترح لتمية التعبير الفني لدى الأطفال قابلي التعلم بالاستفادة من الفنون الحديثة، رسالة دكتوراه غير منشورة، كلية التربية النوعية، جامعة عين شمس. -مجدي عبد الكريم حبيب(r + . ץ).اختبار الكفاءة الاجتماعية، النهضة العربية : القاهرة. - محمد البسيوني(ب99 (19)، أسس التربية الفنية،ط7،عالم الكتب : القاهرة.

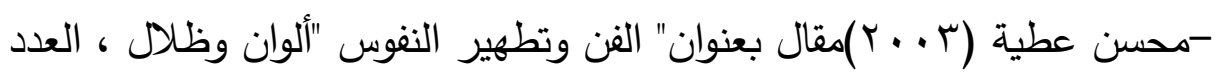

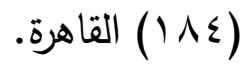

- مروة جمعة محمد أحمد(Y I ب).أنشطة مقترحة في الفن التثكيلي كوسائل اتصال لتحسين مهارات التفاعل الاجتماعي والدمج للطفل التوحدي، رسالة دكتوراه، كلية التربية ، جامعة حلوان. - معاوية أبو غزال(9 . . r).الاستقواء وعلاقته بالشعور بالوحدة والدعم الاجتماعي. المجلة الأردنية في

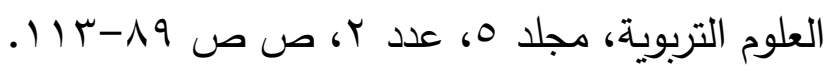


-مجدي محمد الدسوقي (T ( ب).مقياس السلوك ألتمري للأطفال والمراهقين. القاهرة: مكتبة الأنجلو المصرية.

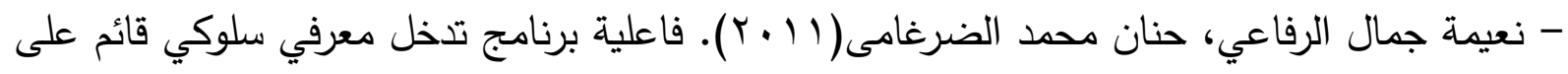
الضبط الذاتي في تحسين الكفاءة الاجتماعية وخفض السلوك المفاعية المعادي للمجتمع لاى عينة في مرحلة المراهقة المبكرة. الملتقى السنوي السابع بعنوان" الصحة النفسية والاجتماعية والمجتمع " بكلية العلوم الاجتماعية. كلية التربية. جامعة المنوفية. - ندا نصر الدين خليل محمد غريب(1 ( • ؟). العلاقة بين التتمر المدرسي لاى تلاميذ المرحلة الإعدادية وبعض خصائص الشخصية والعلاقات الأسرية، جامعة عين شمس، كلية البنات للآداب والعلوم والتربية.

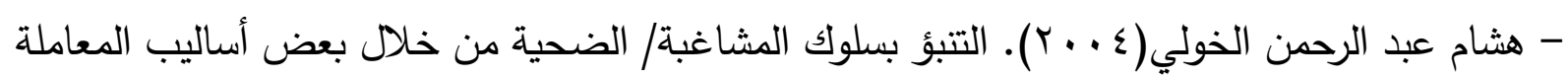
الوالدية السلبية لاى عينة من المراهقين. المؤتمر السنوي الحادي عشر للإرشاد النفسي، مركز الإرشاد

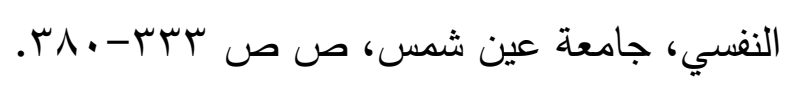
- هاني عتريس(99 (9 (). المهارات الاجتماعية وتقدير الذات والثعور بالوحدة النفسية لدى طلاب الجامعة. رسالة ماجستير • كلية الآداب · جامعة الزقازيق.

- Bonnie, B. C.(2003) Bullying: The T/TAC telegram. New Dimensions in Behavior, Vol.7(3),PP.1-8.

- Bidwell,(1997).the nature and prevalence of bullying in elementary school. Retrieved

from: http://WWW.saskschoollboards.ca.

- Claire. L'\& Michael. B. (2005). The social skills problems of victims of bullying: Self, peer and teacher perception. British Journal of Educational Psychology (2005).75,313-328.

-Carey, T. (2003)Improving the success of anti- bullying programs :A tool for machining programs with intervention purposes. International Journal of Reality THERAPY, 23(2),16-23.

-Coy,D.R.(2001).bullying. American Educational Research Association Conference ERIC Digest, Washington pc.u.s.Department of Education and justice.

- Hrrite Wodeson(1980)"Art therapy" N.J.John wiley \& sons. 
-Horwood, J.;Waylen, A. Williams, C., \& Wolke, d.(2005). Common visual defects and peer victimization in children. Investigative Ophthalmology and Visual Science,Vol. 46(4),1177-1181.

-Keith,S.,Mark,C.,\& Ginny,S.(2004).bullying in secondary school: What it looks like and how to manage it? Paul Chapman Publishing.

- Nainis, N.and paice; j.(2006); Relieving Symptoms in Cancer;Innovative use of art therapy; Journal of pain And Symptom management ;31;2.

- Olweus,D. (1993).Bullying at school: What we know and what we can do. Oxford:Blackwell.

- Rigby,K.\& Slee ,P.(1991)Bullying among Australian school children Repeated behavior and attitudes toward victims Journal of Social Psychology (131)615627.and bullying behaviors?. Health Promotion Practice. 14. (4):599-606.

- Smith-Heavenrich, S. (2001). Kids hurting kids: Bullies in the schoolyard. Mothering Magazine,Vol.7(12).PP. 43-59.

- Tendam,G.,\& Volman.M.(2003).A life jacket or of art of living: Inequality in social competence education .Available at ERIC Database.

-Woods,S.,Hall,L.\& wolk,D.(2007). Implications of gender differences for the development of animated Characters for the study of bullying behavior. Computers in Human Behavior,23(1),770-786.

- Wexler,Alice (2002): Studies in art education, painting their way out: profiles of adolescent art practice at the Harlem hospital horizon art studio. A journal of issues and research,43(4).339-353, state university of New Paltzll. 